\title{
REVIEW
}

\section{The molecular basis of insulin-stimulated glucose uptake: signalling, trafficking and potential drug targets}

\author{
Sophie E Leney and Jeremy M Tavaré \\ Department of Biochemistry, School of Medical Sciences, University of Bristol, Bristol BS8 1TD, UK \\ (Correspondence should be addressed to J M Tavaré; Email: j.tavare@bris.ac.uk)
}

\begin{abstract}
The search for the underlying mechanism through which insulin regulates glucose uptake into peripheral tissues has unveiled a highly intricate network of molecules that function in concert to elicit the redistribution or 'translocation' of the glucose transporter isoform GLUT4 from intracellular membranes to the cell surface. Following recent technological advances within this field, this review aims to bring together the key molecular players that are thought to be involved in
\end{abstract}

GLUT4 translocation and will attempt to address the spatial relationship between the signalling and trafficking components of this event. We will also explore the degree to which components of the insulin signalling and GLUT4 trafficking machinery may serve as potential targets for the development of orally available insulin mimics for the treatment of diabetes mellitus.

Journal of Endocrinology (2009) 203, 1-18

\section{Introduction}

Glucose homeostasis and diabetes mellitus

The ability of insulin to stimulate glucose uptake into muscle and adipose tissue is central to the maintenance of wholebody glucose homeostasis. Autoimmune destruction of the pancreatic $\beta$-cells results in a lack of insulin production and the development of type I diabetes mellitus (T1DM). Deregulation of insulin action manifests itself as insulin resistance, a key component of type II diabetes mellitus (T2DM). Both forms of diabetes confer an increased risk of major lifelong complications. In the case of insulin resistance, this includes a fivefold increased risk of coronary vascular disease. The need for an effective treatment for both forms of diabetes as well as for the development of early detection methodologies has, therefore, become increasingly important. Yet for this to be possible, we must first understand the mechanism through which insulin regulates glucose uptake and identify the key molecular players involved.

\section{The insulin-responsive glucose transporter isoform GLUT4}

The effect of insulin on glucose transport into muscle and adipose first became apparent in the 1950s when several groups demonstrated that insulin was able to accelerate the rate of glucose uptake into these tissues (Park \& Johnson 1955,
Levine \& Goldstein 1958). However, the mechanism by which insulin is able to stimulate glucose uptake was not elucidated until the early 1980s when two independent groups demonstrated that insulin promoted the movement of a 'glucose transport activity' from an intracellular membrane pool to the plasma membrane (Cushman \& Wardzala 1980, Suzuki \& Kono 1980). In 1989, the glucose transporter GLUT4 was cloned and shown to be the major isoform responsible for enhanced glucose uptake into muscle and adipose tissue following the secretion of insulin into the bloodstream (Birnbaum 1989, Charron et al. 1989, Fukumoto et al. 1989, James et al. 1989, Kaestner et al. 1989). Evidence that GLUT4 redistributes from an intracellular membrane pool to the plasma membrane upon insulin stimulation has since been confirmed using a variety of different methods. These have included subcellular fractionation (Marette et al. 1992, Pilch et al. 1993, Deems et al. 1994), electron and fluorescence microscopy (Voldstedlund et al. 1993), bis-mannose photolabelling of plasma membranes (Calderhead et al. 1990, Holman et al. 1990) and more recently the use of exogenously expressed GLUT4 fusion proteins with various epitopes (Czech et al. 1993, Kanai et al. 1993, Dobson et al. 1996, Dawson et al. 2001). All these methods have consistently demonstrated that in non-stimulated cells, the majority of GLUT4 is found within intracellular membranes with $<5 \%$ of the 
total GLUT4 pool present at the plasma membrane. Following insulin stimulation, up to $50 \%$ of the total GLUT4 pool redistributes from its intracellular location to the plasma membrane.

\section{Subcellular localisation of GLUT4}

Identifying the nature of the intracellular compartment(s) in insulin-responsive tissues where GLUT4 resides in the absence of insulin is key to understanding the mechanism through which insulin promotes the redistribution of this GLUT4 pool to the cell surface. Early studies involving the isolation of GLUT4-containing vesicles identified numerous GLUT4 vesicle resident proteins that were known to localise to distinct intracellular compartments, suggesting that GLUT4 localises to several different membrane pools (Tanner \& Lienhard 1987, 1989, Kandror \& Pilch 1994a,b, 1996, Hanpeter \& James 1995, Keller et al. 1995). These observations were supported by immunofluorescence and electron microscopy studies in insulin-responsive tissues, which demonstrated that GLUT4 is localised within complex tubulovesicular structures at the perinuclear region of the cell, to small peripheral vesicles in the cytoplasm and to clathrincoated pits at the cell surface (Friedman et al. 1991, Slot et al. 1991, Smith et al. 1991, Bornemann et al. 1992). Colocalisation studies using known protein markers confirmed that GLUT4 localises to numerous intracellular organelles that include the Golgi complex, the trans-Golgi network, lysosomes, the late endosomes and the recycling endosomes (Ralston \& Ploug 1996). Intriguingly, the predominant intracellular GLUT4 pool was found to constitute a subset of vesicles that display a similar morphology to that of recycling endosomes yet are biochemically distinct and lack common endosomal markers such as the transferrin receptor (TfR) and GLUT1 but are enriched in GLUT4, IRAP and the v-SNARE VAMP-2 (Malide et al. 1997, Ross et al. 1997). This subset of GLUT4 vesicles are often referred to as GLUT4 storage vesicles (GSVs) or the specialised GLUT4 pool, which form during adipogenesis (for recent reviews on this topic see (Hou \& Pessin 2007, Pilch 2008)).

\section{Regulated GLUT4 trafficking}

How insulin stimulates the net translocation of GLUT4 to the plasma membrane has been the subject of intense investigation. To explore this, we will first discuss how GLUT4 is sequestered away from the plasma membrane in the basal state, and how insulin action may impact on these processes. We will then discuss insulin signalling itself in more detail, before moving on to a detailed discussion of the trafficking events that occur at the plasma membrane because our understanding of this area of GLUT4 biology has increased significantly in the past 2-3 years.
Mechanism of GLUT4 sequestration in the absence of insulin

The existence of an insulin-responsive GSV pool to which GLUT4 is targeted in the absence of insulin is supported by many studies and is widely accepted within the field. However, the mechanism by which GLUT4 is actively retained within this compartment and thereby sequestered away from the plasma membrane in the basal state remains controversial. Currently, evidence exists to support two entirely different mechanisms of GLUT4 sequestration.

Studies in both 3T3-L1 adipocytes (Martin et al. 2006) and rat adipose cells (Satoh et al. 1993, Yang \& Holman 1993) have suggested that GLUT4 is continuously cycled between the plasma membrane and intracellular membrane compartments and appears to maintain its intracellular localisation through a combination of slow exocytosis and rapid endocytosis. Additional studies in 3T3-L1 adipocytes have suggested that the slow recycling of GLUT4 is due to a dynamic sorting process that involves the continuous budding and fusion of GLUT4-containing vesicles between the endosomal compartment and the GSVs (Karylowski et al. 2004). This continuous cycle of 'release and capture' is thought to actively prevent the net recycling of GLUT4 back to the plasma membrane and may therefore be an important site of regulation by insulin. This study also supports the hypothesis that GSVs are a post-endosomal pool, a theory formulated based on the observation that the disruption of the function of certain proteins (including Rab11 (Zeigerer et al. 2002), Syntaxin16 (Proctor et al. 2006), EHD1 (Guilherme et al. 2004), Ubc9 (Liu et al. 2007), Syntaxin6 (Perera et al. 2003) TUG (Yu et al. 2007), Rabip4 (Mari et al. 2006)) leads to the accumulation of GLUT4 within endosomes and enhanced cell surface levels. Collectively, these observations have led to the 'dynamic retention' hypothesis in which the entire GLUT4 pool is in dynamic equilibrium between the cell surface and intracellular compartments. In this model, insulin signalling is thought to elicit changes in the rates of GLUT4 exocytosis and endocytosis to achieve a new steadystate distribution of GLUT4 with up to $50 \%$ of the total GLUT4 pool present at the plasma membrane. In this model, as illustrated in Fig. 1, GLUT4 could translocate to the plasma membrane via either route 1 (direct fusion with the plasma membrane), route 2 (re-entry into a recycling pool) or a combination of both.

Govers et al. (2004) have proposed an alternative model to explain the intracellular retention of GLUT4. They found that up to $90 \%$ of the total GLUT4 pool in 3T3-L1 adipocytes is stored within intracellular compartments that are not in equilibrium with the cell surface under non-stimulated conditions (Govers et al. 2004). Here, insulin was found to increase the amount of GLUT4 present within a cycling pool that exchanges with the plasma membrane and, interestingly, the degree to which GLUT4 was released into this pool was proportional to the insulin dose (in a process termed 'quantal release'; Govers et al. 2004). It is likely that this model involves the translocation of GLUT4 to the plasma membrane via 


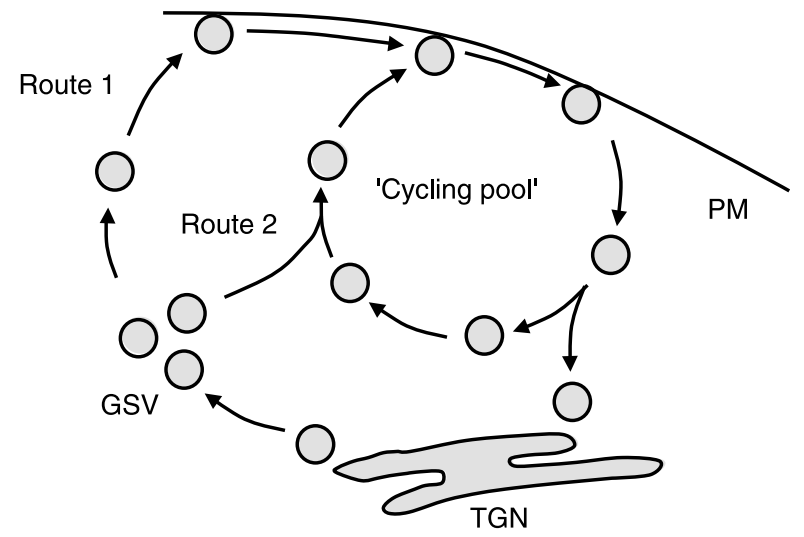

Figure 1 GLUT4 trafficking pathways: the dynamic versus static retention models. In the absence of insulin, any GLUT4 found in the plasma membrane (PM) is endocytosed into early endosomes before sorting into the GLUT4 storage compartment (GSV), possibly by trafficking via the trans-Golgi network (TGN). GLUT4 is then sequestered within the GSV pool through either a 'dynamic' or 'static' retention process, details of which can be found in the main text. Upon addition of insulin, GLUT4 traffics back to the plasma membrane either via a direct exocytic route (route 1) or by 'quantal release' back into a recycling pool (route 2). The nature of the 'cycling pool' is not well understood but may be enriched in GLUT1 and the transferrin receptor.

a pathway akin to route 2 (Fig. 1), although this remains to be established. These findings have led to the proposed 'static retention' model in which GLUT4 is actively retained within a storage pool that, once formed, does not 'communicate' with other intracellular compartments in the absence of insulin (Govers et al. 2004).

The fundamental discrepancy between these two models has been recently addressed in an interesting study by Muretta et al. (2008). They demonstrated that the process of replating transfected 3T3-L1 adipocytes before analysis, as performed by Martin et al. (2006) but not by Govers et al. (2004), disrupted the intracellular retention of GLUT4 within a static storage pool, resulting in the continuous cycling of GLUT4 between the plasma membrane and the intracellular compartment(s). On the basis of these observations, the authors have concluded that the static retention model predominates over the dynamic retention model in 3T3-L1 adipocytes.

It is also important to note that 3T3-L1 adipocytes possess a very different cellular architecture to the native adipocyte in situ. In 3T3-L1 adipocytes, much of the intracellular GLUT4 is found within the perinuclear region in addition to small peripheral cytoplasmic vesicles, meaning that GLUT4 is often located a significant distance away from the plasma membrane. In freshly isolated primary adipocytes and intact adipose tissue, however, GLUT4 vesicles are already in close proximity to the plasma membrane in the basal state due to the single large fat droplet present in this cell type (that makes up as much as $99 \%$ of the total cell volume), which extrudes the cytoplasm and its constituent tubulovesicular compartments into a thin sub-plasma membranous layer. Thus, there is no obvious requirement for long-range translocation of GLUT4 from deep intracellular compartments to the plasma membrane in native adipocytes. To what extent, therefore, the dynamic and static retention models play a role in primary and native adipocytes is not known, nor is the degree to which these models account for GLUT4 translocation in intact muscle where GLUT4 translocates to both the sarcolemma and t-tubules (Lauritzen et al. 2008).

At which intracellular trafficking steps does insulin signalling promote the translocation of GLUT4 to the plasma membrane?

The static retention model would require that the insulin signal enter deep into the cell and trigger the release of GLUT4 from the sequestered pool(s) into the continuously cycling system, and from there traverse towards the plasma membrane. On this basis, insulin would stimulate flux through route 2 (Fig. 1). If correct, then the mechanism by which insulin might release GLUT4 from the sequestered store in this model is not known. GLUT4 may be retained in the sequestered pool via its tethering to the protein TUG (Bogan et al. 2003, Yu et al. 2007), and insulin has been reported to release GLUT4 from this complex (Bogan et al. 2003) but how it does this is not yet fully understood.

Once released into the cycling pool, GLUT4 must then traverse the cytoplasm towards the plasma membrane before docking and fusing with it. Some studies have reported that vesicles containing GFP-tagged GLUT4 translocate towards the plasma membrane along microtubules and that this process is regulated by insulin in a PI3-kinase-independent but kinesin-dependent manner (Semiz et al. 2003). However, while we also observe microtubule-driven movements of GLUT4 in 3T3-L1 adipocytes, these are predominantly towards the perinuclear region from the plasma membrane (Fletcher et al. 2000, Berwick et al. 2004). This observation is consistent with other studies showing that microtubule depolymerising agents disperse GLUT4 from the perinuclear region (Molero et al. 2001, Shigematsu et al. 2002) and block GLUT4 internalisation (Shigematsu et al. 2002), suggesting that intracellular sorting of GLUT4 is disrupted by the drugs. Taken together, the data suggest that microtubules are unlikely to play a major role in the directed movement of GLUT4-containing vesicles to the plasma membrane.

Under the dynamic retention model, insulin could stimulate the net translocation of GLUT4 to the cell surface via a fundamentally different mechanism. In this model, the majority of intracellular GLUT4 in the basal state is in dynamic equilibrium with the plasma membrane and so must be on vesicles that are constantly arriving at and fusing with the plasma membrane before the GLUT4 is endocytosed and recycled back into intracellular compartments. In this model, therefore, insulin need only shift the state of this equilibrium by increasing the rate constants for docking and/or fusion of the vesicles with the plasma membrane. In this case, there 
would be no need to invoke an effect of insulin on the release of GLUT4 from deep intracellular compartments.

Insulin also stimulates GLUT1 and TfR translocation to the plasma membrane, although the magnitude of the insulin effect (twofold or less) is considerably lower than that observed for GLUT4 and TfR translocation, at least in adipocytes. This may be due to the fact that GLUT4 is sequestered away from the plasma membrane in the basal state, whereas GLUT1 and TfR are largely found in recycling endosomes and so significant amounts of GLUT1 and TfR are found in the plasma membrane under equivalent conditions. However, the static and dynamic retention models will also need to take account of the mechanism by which insulin stimulates GLUT1 and TfR translocation. At present, this is a particularly poorly understood area.

Clearly much further work is required to clarify which of the dynamic and static retention models are operational in 3T3-L1 adipocytes, rat adipocytes, and human fat and muscle cells, before we can be sure where insulin acts on GLUT4 trafficking. This area must therefore remain a priority for further investigation.

\section{Insulin signalling to GLUT4 trafficking}

Activation of the insulin receptor by insulin elicits a wide range of cellular responses that together coordinate a shift in the steady-state distribution of GLUT4 to the cell surface. The molecular events that facilitate this process range from the formation of large scaffolding complexes that coordinate signalling molecules, the activation of numerous protein kinases, the rearrangement of cytoskeletal components and the formation and/or activation of machinery that facilitates both the movement to and fusion of GLUT4 vesicles with the plasma membrane. However, despite an ever-growing list of potential molecules that appear to be required for insulin-stimulated GLUT4 translocation, numerous gaps remain in our understanding of the complete signal transduction pathway that begins at the insulin receptor and culminates with the fusion of GLUT4 vesicles with the plasma membrane.

\section{Early signalling events at the plasma membrane}

The activation of the insulin receptor by insulin is thought to stimulate two independent signal transduction pathways that converge at the level of GLUT4 trafficking to bring about the redistribution of the glucose transporter to the cell surface (Fig. 2). The first of these pathways is the well-documented PI3-kinase pathway, in which the class I phosphoinositide $3^{\prime}$ kinase is recruited to the plasma membrane by the insulin receptor substrate (IRS1/2) where it catalyses the conversion of plasma membrane localised $\mathrm{PIP}_{2}$ to $\mathrm{PIP}_{3}$ (Tengholm \& Meyer 2002). The transient increase in plasma membrane $\mathrm{PIP}_{3}$ following insulin receptor activation results in the recruitment of proteins containing pleckstrin homology $(\mathrm{PH})$ domains to the cell surface. In muscle and adipose tissue, this includes the recruitment of the $\mathrm{PH}$ domain-containing serine/threonine protein kinases protein kinase $\mathrm{B}$ ( $\mathrm{PKB}$ or $\mathrm{Akt}$ ) and PDK1. Once recruited to the plasma membrane, $\mathrm{PKB} / \mathrm{Akt}$ is activated by phosphorylation on Thr308 by PDK1 (Alessi et al. 1997, Stokoe et al. 1997, Stephens et al. 1998) and on Ser473 by TORC2 (Hresko \& Mueckler 2005, Sarbassov et al. 2005). The evidence to support a role for $\mathrm{PKB} / \mathrm{Akt}$ in insulin-stimulated glucose uptake is overwhelming and includes the ability of constitutively active $\mathrm{PKB} / \mathrm{Akt}$ mutants to recapitulate the effects of insulin on GLUT4 translocation and glucose uptake (Kohn et al. 1996, Andjelkovic et al. 1997, Tanti et al. 1997, Ducluzeau et al. 2002, Chen et al. 2003, Ng et al. 2008), the inhibition of insulin-stimulated GLUT4 translocation and glucose uptake by various dominant-negative $\mathrm{PKB} / \mathrm{Akt}$ mutants (Cong et al. 1997, Wang et al. 1999), siRNA-mediated knockdown (Katome et al. 2003), competing antibodies (Hill et al. 1999) and small molecule PKB/Akt inhibitors (Gonzalez \& McGraw 2006, Green et al. 2008), and the generation of PKB $\beta$ knockout mice that develop insulin resistance and diabetes (Cho et al. 2001, Garofalo et al. 2003, Dummler et al. 2006). Atypical isoforms of $\mathrm{PKB} \lambda / \zeta$ have also been reported to be important in the mechanism by which insulin stimulates GLUT4 translocation (Bandyopadhyay et al. 1997a,b, Lorenzo et al. 2002, Imamura et al. 2003, Liu et al. 2006), although how they do this is very poorly understood.

A wortmannin-insensitive pathway has also been proposed that functions in parallel to PI3K activation. This pathway involves the recruitment and tyrosine phosphorylation of $\mathrm{c}-\mathrm{Cbl}$, a proto-oncogene, to the activated insulin receptor via two adaptor proteins, APS and CAP, an interaction which is further stabilised through an association with the lipid raft protein flotillin (Ribon \& Saltiel 1997, Ribon et al. 1998). Phosphorylated c-Cbl recruits the adaptor protein CrKII and the guanine nucleotide exchange factor, $\mathrm{C} 3 \mathrm{G}$, to lipid rafts where C3G specifically activates the small GTP binding protein TC10. Downstream substrates of TC10 include CIP4/2 (Chang et al. 2002), N-WASP (Jiang et al. 2002) and possibly Exo70 (Inoue et al. 2003, 2006). The activation of this pathway by insulin is thought to regulate several different processes including cortical actin rearrangements (Kanzaki \& Pessin 2001), PI(3)P formation at the plasma membrane (Maffucci et al. 2003), recruitment of the exocyst complex to the plasma membrane via Exo70 (Inoue et al. 2003, 2006) and the inactivation of Rab31 (Lodhi et al. 2007). The importance of this pathway in insulin-stimulated glucose uptake is however, controversial due to conflicting siRNA and mouse knockout studies. In a study by Chang et al. (2007), knockdown of TC10 $\alpha$ but not TC10 $\beta$ in 3T3-L1 adipocytes leads to a partial inhibition of both insulin-stimulated glucose uptake and GLUT4 translocation. However, the siRNAmediated ablation of Cbl, CAP and CrkII do not have any significant effect on insulin-stimulated glucose uptake or GLUT4 translocation (Mitra et al. 2004, Zhou et al. 2004). Furthermore, while the generation of $\mathrm{Cbl}$ knockout mice 


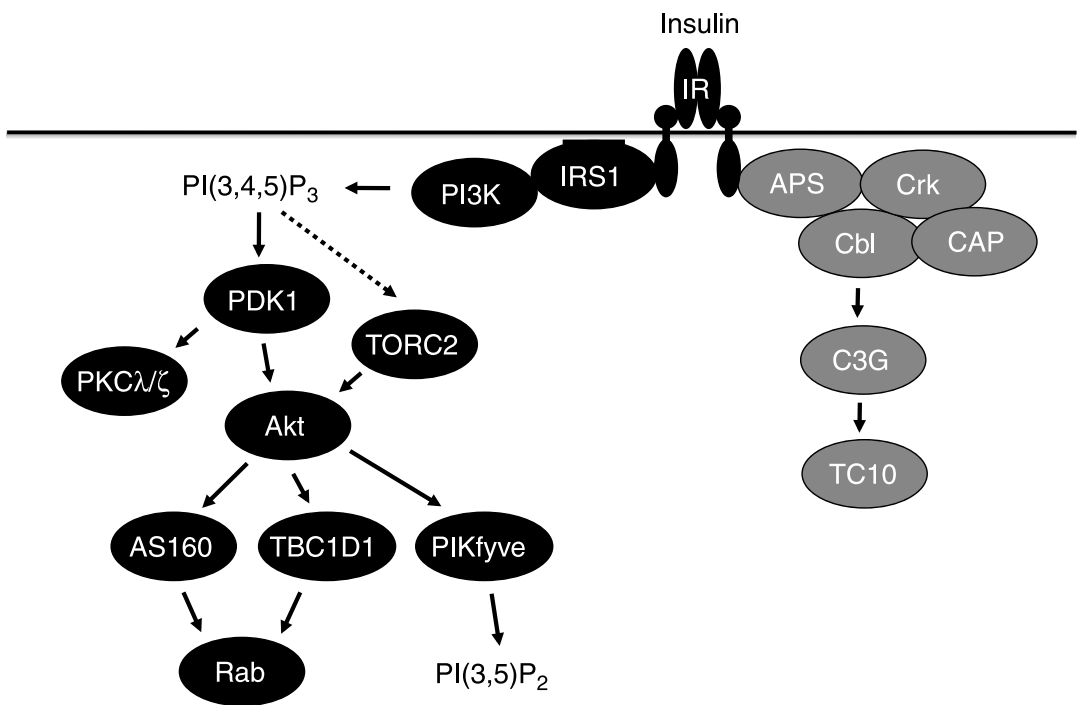

Figure 2 Insulin signalling pathways implicated in GLUT4 translocation. This figure illustrates the major signalling pathways implicated in insulin action of glucose transport. These include the PI3-kinase-dependent (black) and -independent (grey) pathways. See text for further details.

does not result in a significant difference in insulin sensitivity (Molero et al. 2004), APS knockout mice show enhanced insulin sensitivity and hypoinsulinaemia (Minami et al. 2003). Finally, studies performed in muscle cells indicate that TC10 signalling may not be required for cortical actin rearrangements as has been shown in adipocytes (JeBailey et al. 2004). Taken together, the data suggest that the APS-Cbl-C3G pathway plays a relatively minor role in insulin-stimulated GLUT4 translocation.

\section{Signalling downstream of $\mathrm{PKB} / \mathrm{Akt}$}

Since the identification of $\mathrm{PKB} / \mathrm{Akt}$ as a major target of $\mathrm{PI} 3 \mathrm{~K}$ activity and its central role in insulin-stimulated glucose uptake, the identification of $\mathrm{PKB} / \mathrm{Akt}$ substrates that link upstream insulin signalling events to GLUT4 translocation has provided the focus for many research groups worldwide. Two notable substrates are the Rab GTPase-activating protein (RabGAP), AS160 and the phosphoinositide 3P-5-kinase, PIKfyve.

\section{Akt substrate of $160 \mathrm{kDa}$}

Akt substrate of $160 \mathrm{kDa}$ (AS160; also known as Tbc1d4) was first identified in a screen of 3T3-L1 adipocytes using a commercially available antibody that reacts with the $\mathrm{PKB} / \mathrm{Akt}$ phosphorylation motif (RXRXXpS/T; (Kane et al. 2002)). AS160 contains two phosphotyrosine binding domains (PTB), a GAP domain selective for Rab small GTP-binding proteins and seven potential $\mathrm{PKB} / \mathrm{Akt}$ phosphorylation sites of which six are phosphorylated in vivo (Kane et al. 2002, Sano et al. 2003). The generation of a phosphorylation mutant called $\mathrm{AS} 160_{4 \mathrm{~B}}$ in which four of the six phosphorylation sites are mutated to alanine residues, dominantly inhibits the insulin-stimulated translocation of a GLUT4 reporter construct to the plasma membrane when co-expressed in 3T3-L1 adipocytes (Sano et al. 2003). Mutation of Arg973 within the RabGAP domain of AS160, which renders the GAP domain inactive, relieves the inhibitory effect of the phosphorylation mutant, suggesting that it is the active GAP domain that is responsible for preventing GLUT4 translocation (Sano et al. 2003). These observations indicate that AS160 functions as a negative regulator of GLUT4 trafficking under non-stimulated conditions where the active GAP domain of AS160 suppresses the activity of a Rab or multiple $\mathrm{R} a b$ proteins that in their active forms are required for GLUT4 translocation to occur. This hypothesis is supported by siRNA studies that demonstrate that following the ablation of AS160 from adipocytes, plasma membrane GLUT4 levels become elevated in the absence of insulin (Eguez et al. 2005, Larance et al. 2005). However, it should be noted that over-expression of the AS160 4 P mutant, while dominant inhibitory, does not completely block insulin-stimulated glucose uptake into adipocytes. Furthermore, knockdown of AS160 using siRNA-mediated ablation has a relatively weak stimulatory effect on basal glucose uptake. These data have been taken to suggest that the AS160 pathway is not the only pathway by which insulin regulates glucose uptake, although this remains to be firmly established.

The phosphorylation of AS160 is thought to render the GAP domain inactive and therefore relieve the inhibitory effect of AS160 on its target $\mathrm{Rab}(\mathrm{s})$; however, it remains unclear how this is achieved mechanistically. There is evidence to indicate that AS160 is present on GLUT4 


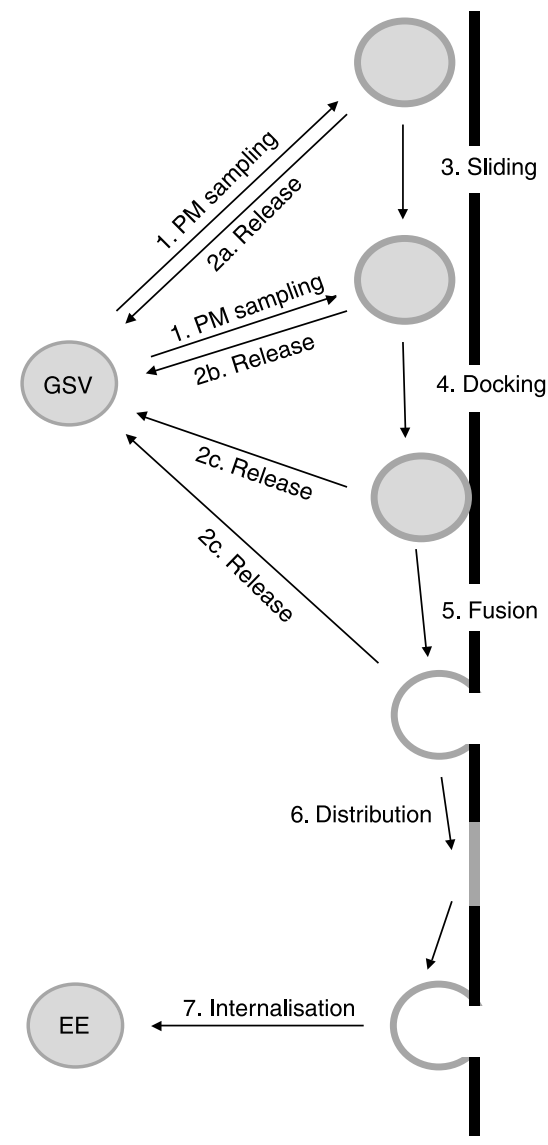

Figure 3 Events in GLUT4 trafficking occurring within $150 \mathrm{~nm}$ of the plasma membrane. The figure provides a putative model based on data acquired using, at least in part, TIRF microscopy. In step 1, GLUT4 storage vesicles (GSV) arrive from the bulk cytosol and sample the plasma membrane for appropriate docking sites. Vesicles juxtapositioned at the membrane are either released directly back into the cytosol (step 2a) or slide along putative actin filaments (step 3) until they either dock (step 4) or are released back into the cytosol again (step 2b). The docking process is regulated by insulin (Fig. 4A), as is the subsequent process of fusion with the plasma membrane (step 5; see also Fig. 4B). Docked and fused vesicles may also be released from the plasma membrane back into the cytosol (so-called 'kiss and run' events; steps 2c). Once a vesicle has fused, the GLUT4 contents distribute into the plasma membrane before a process of internalisation into early endosomes (EE) commences (step 7). Insulin stimulates steps 4 and 5, and inhibits step 7 that leads to a net increase in plasma membranelocalised GLUT4. Insulin may also stimulate step 3. See text for further details.

vesicles under basal conditions (Larance et al. 2005, Miinea et al. 2005) but is released into the cytosol upon stimulation with insulin where it associates with 14-3-3 binding proteins (Ramm et al. 2006). This would suggest that the phosphorylation of AS160 leads to its dissociation from GLUT4 vesicles by facilitating its binding to $14-3-3$ proteins that recognise their target proteins by binding to phospho-threonine or phospho-serine residues. However, a study by Stöckli et al. (2008) has shown that the phosphorylation of AS160 but not its dissociation from membranes is essential for insulinstimulated GLUT4 translocation. The association of AS160 with GLUT4 vesicles has been shown to involve an interaction between the $\mathrm{N}$-terminus of IRAP and amino acids 367 to 1299 of AS160 that comprises the second PTB domain, the RabGAP domain and four out of the six PKB phosphosphorylation motifs (Peck et al. 2006). In support of the study by Stöckli et al. mutation of two AS160 phosphosphorylation sites, Ser588 and Thr642, to either alanine or aspartic acid to mimic dephosphorylation and phosphorylation respectively, had no effect on the interaction between AS160 and IRAP. Similarly, the interaction between endogenous AS160 and IRAP was unchanged by insulin. However, the AS160-IRAP interaction has also been reported by a separate group and in this study, insulin treatment significantly reduced the interaction of AS160 with IRAP.

The isolated GAP domain of AS160 is active in vitro against the purified forms of Rabs 2A, 8A, 10 and 14 (Miinea et al. 2005). Interestingly, studies have revealed that in adipose cells, Rab10 appears to be the isoform regulated by AS160 (Sano et al. 2007, 2008) whereas in muscle cells, the isoforms are Rabs 8A and 14 (Ishikura et al. 2007). These findings are based on: a) their ability, when over-expressed as GTP-locked mutants, to rescue the inhibitory effects on GLUT4 trafficking of either the dominant-negative $\mathrm{AS} 160_{4 \mathrm{P}}$ mutant or of siRNA-mediated AS160 knockdown, and b) the effect of siRNA-mediated depletion of the Rab isoform on insulinstimulated glucose transport in adipocytes or muscle cells. However, given that $\mathrm{Rab}$ proteins are involved in a plethora of intracellular trafficking events, both these experimental approaches should be approached with some caution since the perturbation of any intracellular GLUT4 trafficking step, whether directly involved in the delivery of GLUT4 to the plasma membrane or not, could inhibit insulin-stimulated GLUT4 translocation. For example, if the Rab were involved in the formation and/or maturation of the GSV pool, then its knockdown would indirectly reduce insulin-stimulated GLUT4 translocation by blocking the sorting of GLUT4 into the insulin-responsive GSV pool. Since it is difficult to assess the integrity of this compartment, and until technologies for studying GLUT4 trafficking improve, indirect effects on GLUT4 translocation are going to be difficult to eliminate from any particular enquiry. However, for a more comprehensive review of the role of Rabs in insulin action, the reader is directed to two recent reviews (Ishikura et al. 2008, Kaddai et al. 2008).

AS160 is expressed in tissue and muscle, as well as several other tissues at least at the level of mRNA. Interestingly, AS160 shares $~ 50 \%$ identity at the amino acid sequence level with the product of the TBC1D1 gene that probably appeared first during the evolution of this class of GAP. Expression of AS160 appears to predominate over TBC1D1 in both adipose tissue and slow twitch muscle fibres, whereas TBC1D1 is more abundant in fast twitch muscle fibres (Taylor et al. 2008). 
Both AS160 and TBC1D1 possess a set of tandem PTB domains at their N-termini, and highly related GAP domains at their C-termini but where the two proteins particularly differ is in their phosphorylation. AS160 possesses a total of up to eight different phosphorylation sites, whereas TBC1D1 possesses just two, at least in cells stimulated with insulin, AMP kinase activators and insulin-like growth factors (Geraghty et al. 2007, Jiang et al. 2008). Furthermore, although both proteins possess binding sites for 14-3-3 proteins, the binding sites involved differ significantly (Geraghty et al. 2007, Jiang et al. 2008). In addition to a role in insulin-stimulated glucose uptake in muscle, as discussed above, TBC1D1 is likely to play an important role in the stimulation of muscle glucose uptake in response to contraction and activators of AMP kinase (Taylor et al. 2008), which would make this protein an important coordinator of diverse signalling pathways that are known to regulate glucose uptake in this tissue.

Our understanding of the role of AS160 and TBC1D1 would greatly benefit from the development of knockout and knockin (in which phosphorylation sites in AS160 and TBC1D1 are knocked out individually or in combinations) mouse models. Such mice have yet to be reported; however, a mouse strain (SJL) resistant to high-fat diet-induced obesity has been recently shown to possess a mutation in TBC1D1 that causes premature termination of protein translation (Chadt et al. 2008). Levels of TBC1D1 mRNA were reduced by $70 \%$ in the SJL strain compared with the control congenic strain, and there was no detectable expression of full-length TBC1D1 protein. Insulin-stimulated glucose uptake in extensor digitorum longus muscles isolated from SJL mice was reduced compared with that in the control congenic strain, but basal uptake rates were not different. This is a surprising result given that siRNA-mediated ablation of AS160 in cell lines increases basal glucose uptake (Eguez et al. 2005, Larance et al. 2005). However, the SJL mouse may still express a truncated version of TBC1D1 lacking GAP activity and this may act as a dominant-negative inhibitor of glucose uptake into muscles, so complicating the interpretation of the phenotype.

SJL mice exhibit increased muscle palmitate uptake and oxidation, when compared with a congenic control strain that is susceptible to high-fat diet-induced obesity. However, whether this is related to the obesity-resistant phenotype of the SJL strain was not established. As TBC1D1 is expressed in the hypothalamus, a possible role for the protein in appetite control cannot be discounted. In further support of a role of TBC1D1 in weight control, a W125R coding variant within the $\mathrm{N}$-terminal PTB domain of TBC1D1 is linked to an increased risk of severe obesity in females in an American cohort (Stone et al. 2006), an observation that has now been replicated in a French cohort (Meyre et al. 2008), although the mutation is not associated with milder forms of obesity in the general population. Again, the molecular basis for this genotype-phenotype relationship is not known.

\section{PIKfyve}

Several studies now point to an important role of the phosphoinositide 3P-5-kinase, PIKfyve, in insulin action on glucose uptake. This protein not only binds to PI3P via its N-terminal FYVE domain, but it also phosphorylates PI3P to yield $\mathrm{PI}(3,5) \mathrm{P}_{2}$. Shisheva's group has reported that over-expression of a kinase-inactive PIKfyve as well as siRNA-mediated depletion of PIKfyve block insulinstimulated GLUT4 translocation in adipocytes (Ikonomov et al. 2002, 2007). Our own group has reported that $\mathrm{PKB} /$ Akt phosphorylates Ser318 on purified recombinant GST-PIKfyve and that this leads to an approx. twofold stimulation of the 5-kinase activity of PIKfyve in vitro (Berwick et al. 2004). This is consistent with a recent report that insulin stimulates $\mathrm{PI}(3,5) \mathrm{P}_{2}$ production in intracellular membranes of 3T3-L1 adipocytes (Ikonomov et al. 2007). We showed that insulin stimulates the phosphorylation of Ser318 in cells and that this phosphorylation plays a role in GLUT4 trafficking because over-expression of the non-activatable PIKfyve[S318A] mutant in 3T3-L1 adipocytes enhanced insulin-stimulated GLUT4 vesicle translocation to the plasma membrane (Berwick et al. 2004). This observation is consistent with recent studies showing that pharmacologic inhibition (using the selective PIKfyve inhibitor YM201636 (Jefferies et al. 2008)) and siRNA-mediated knockdown of PIKfyve both potentiate secretory granule exocytosis in chromaffin and PC12 cells (Osborne et al. 2007). Together, however, these observations are not consistent with Shisheva's studies (Ikonomov et al. 2002, 2007) although care should be taken in interpreting experiments where PIKfyve activity has been disrupted by siRNA-mediated knockdown, a kinase-inactive mutant or the PIKfyve inhibitor YM201636 because these manipulations all cause vacuolation of intracellular membranes (Shisheva et al. 2001, Rutherford et al. 2006, Jefferies et al. 2008). Such vacuolation could indirectly block GLUT4 translocation by preventing the sequestration of GLUT4 within the specialised GSV pool. Clearly, further work is required to understand these observations.

We proposed that the phosphorylation and activation of PIKfyve by $\mathrm{PKB} /$ Akt provides a novel signalling paradigm that might link plasma membrane-derived $\mathrm{PIP}_{3}$ signals to intracellular $\mathrm{PI}(3,5) \mathrm{P}_{2}$ production, and thereby to the control of GLUT4 trafficking between endosomes and the TGN, from where GLUT4 may feed into the GSV pool. This is consistent with recent studies demonstrating that PIKfyve is predominantly associated with early endosomes, from where it regulates retrograde membrane trafficking of the mannose-6-phosphate receptor to the TGN (Rutherford et al. 2006).

Additional evidence that PIKfyve phosphorylation is important in intracellular trafficking comes from our observation that Ser318 is a substrate for the protein kinases SGK1 and SGK3. 
Interestingly, we have found that the PIKfyve[S318A] mutant inhibits the trafficking of several metabolite transporters and ion channels to the cell surface (Seebohm et al. 2007, Shojaiefard et al. 2007). That these proteins are invariably found in the recycling endosomal system, rather than a compartment equivalent to the GSV pool containing GLUT4, probably underlies the reason for the inhibitory rather than enhancing effect of the PIKfyve[S318A] mutant observed in these studies.

Purified PKB/Akt phosphorylates recombinant PIKfyve on a second site, as yet unidentified, in addition to Ser318 but this second site is poorly phosphorylated in vitro by SGK3 (Seebohm et al. 2007). When S318A is mutated to alanine, this second site becomes a better substrate for $\mathrm{PKB} / \mathrm{Akt}$ in vitro (E Hill and JMT, unpublished data). However, it remains to be determined whether this second $\mathrm{PKB} / \mathrm{Akt}$ site is phosphorylated on PIKfyve in intact cells or is simply an in vitro artefact.

Interestingly, both insulin and hyperosmotic stress stimulate Ser318 phosphorylation of wild-type PIKfyve and a kinaseinactive mutant of PIKfyve when expressed in CHO.T cells (E Hill and J M T, unpublished observations). Thus, the effect of insulin is not due to autophosphorylation by PIKfyve itself, as claimed by Shisheva (Ikonomov et al. 2007). The response to hyperosmotic stress is also independent of PI3-kinase and $\mathrm{PKB} / \mathrm{Akt}$, but as yet we do not know the kinase involved. Hyperosmotic stress is well known to stimulate glucose uptake in 3T3-L1 adipocytes, also in a PI3-kinase-independent manner (Sakaue et al. 1997) raising the question of whether PIKfyve, at least in part, acts as a point of convergence of insulin and hyperosmolarity signalling with respect to the regulation of glucose transport.

All the phosphorylation sites we have identified to date lie close to the N-terminal FYVE domain of the protein suggesting that phosphorylation could alter the ability of the FYVE domain to interact with PI3P. This in turn could be the reason for the apparent stimulatory effect of phosphorylation on 5-kinase activity we observe (i.e. by recruiting PIKfyve to PI3P substrate containing liposomes used in the assay rather than altering catalytic activity per se (Berwick et al. 2004)). Interestingly, PKC phosphorylates a short linker between the $\mathrm{N}$-terminal $\mathrm{PH}$ domain of Pleckstrin and its neighbouring DEP domain and this has been postulated to regulate the affinity of the $\mathrm{PH}$ domain for phospholipid (Civera et al. 2005). The possibility that a similar phenomenon takes place in PIKfyve warrants investigation.

\section{New perspectives in GLUT4 trafficking: the plasma membrane as an important site of insulin action}

While insulin signalling may regulate the release of GLUT4 from sequestered intracellular storage pools, as discussed above, it has recently become apparent that the hormone also has substantial effects on the docking and fusion of GLUT4 vesicles with the plasma membrane. These observations have come about as a result of the use of total internal reflection fluorescence microscopy (TIRF), a technique that allows a region of between 100 and $250 \mathrm{~nm}$ beneath the plasma membrane to be imaged at high resolution. When used in conjunction with sophisticated image analysis software, this has enabled detailed kinetic analysis of the behaviour of individual GLUT4-containing vesicles through the various stages of their arrival, docking and fusion with the plasma membrane. Figure 3 summarises the steps that occur in this region of the cell.

Studies in both freshly isolated primary rat adipocytes and 3T3-L1 adipocytes have revealed that in the absence of insulin, highly mobile GLUT4 vesicles are observed in the TIRF zone (Lizunov et al. 2005, Bai et al. 2007, Huang et al. 2007). Many of these vesicles are reported to display longrange lateral movements along predefined trajectories (step 3 in Fig. 3) and often become immobilised for a short period of time at specific sites (Lizunov et al. 2005). This behaviour is now widely recognised as docking (i.e. step 4 in Fig. 3), and is thought to involve the association of GLUT4 vesicles with tethering proteins localised to the plasma membrane. In the absence of insulin, many docking events are observed; however, only a small percentage (1\%) result in the fusion of GLUT4 vesicles with the plasma membrane (Jiang et al. 2008). If fusion does not occur, the vesicles are released from their docking sites and disappear from the TIRF zone (step $2 \mathrm{~b}$ in Fig. 3). Based on these observations, the authors have suggested that in non-stimulated cells, GLUT4-containing vesicles are constantly sampling or bombarding the plasma membrane to assess its fusion competency (step 1 in Fig. 3 (Bai et al. 2007)).

Insulin treatment results in a reduction in the mobility of GLUT4 vesicles localised within the TIRF zone (Lizunov et al. 2005); however, the density of vesicles within the evanescent field is increased by only $\sim 20 \%$ (Bai et al. 2007). This observation indicates that the recruitment of GLUT4 vesicles from intracellular membranes to the cell periphery is not the only factor contributing to the redistribution of GLUT4 to the plasma membrane, and so is more consistent with the dynamic rather than the static retention model. Instead it has been proposed that the predominant effect of insulin is to increase both the docking and fusion rate of GLUT4 vesicles with the plasma membrane. Initial TIRF studies using a GFP-tagged GLUT4 calculated that insulin increased the docking rate of GLUT4 vesicles by $\sim$ twofold and their fusion rate by $\sim$ eightfold (steps 4 and 5 , respectively, in Fig. 3 (Bai et al. 2007)). However, in a more recent study, the development of a new reporter fusion protein, pHluorin-IRAP-tDimer2, has demonstrated that insulin stimulates a 42 -fold increase in the rate of GLUT4 vesicle fusion (Jiang et al. 2008).

The development of an in vitro fusion assay has also suggested that the plasma membrane is an important site of insulin action (Koumanov et al. 2005). This assay uses fluorescence resonance energy transfer (FRET) to detect fusion between isolated GLUT4 vesicles and reconstituted 

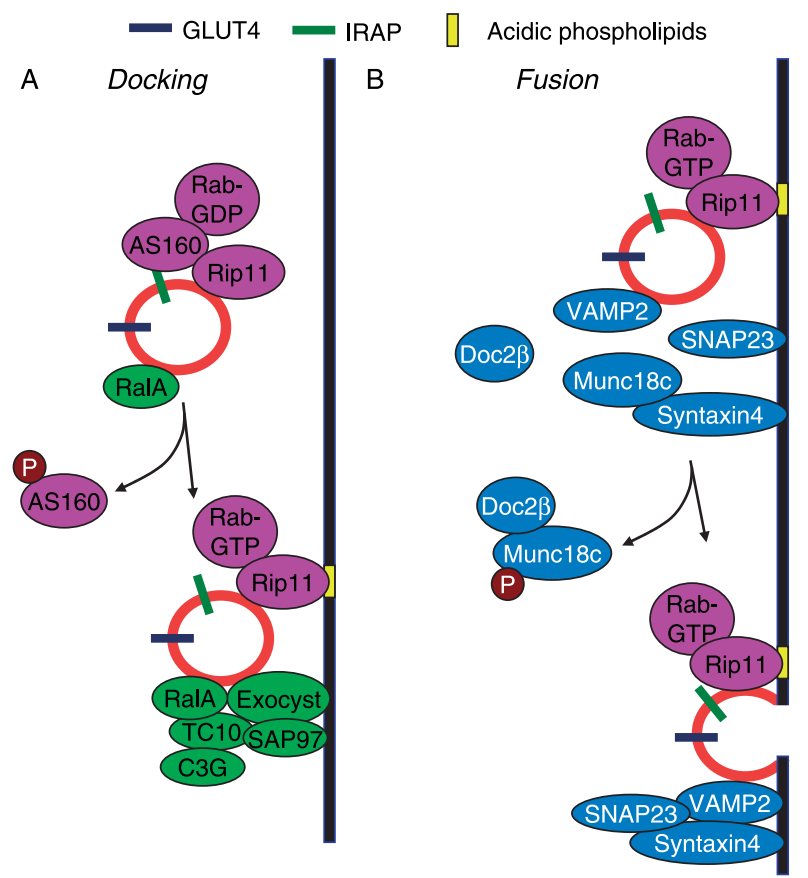

Figure 4 Protein complexes involved in the regulation of GLUT4 vesicle docking (A) and fusion (B) by insulin. (A) Provides detail of the AS160 (magenta) and exocyst (green) complexes that are proposed to play a role in the regulation of GLUT4 (blue bar) vesicle docking with the plasma membrane (see step 4 of Fig. 3). Here, insulin stimulates the activity of PKB/Akt (not shown), which phosphorylates AS160 on multiple sites leading to its release from IRAP (green bar) and Rip11. The Rab becomes activated via GTP loading, now that the GTPase-activating protein AS160 is no longer present. Rip11 binds to acidic phospholipids in the plasma membrane (yellow) and is known to bind Rab proteins in a GTPdependent manner. The identity of the Rab protein activated by AS160 is unknown at this time but could be Rab10 or Rab14, depending on the tissue. At the same time, components of the exocyst complex are recruited to the plasma membrane in a manner that may be regulated by the GTP-binding proteins TC10 and RalA. (B) This diagram exemplifies SNARE and related proteins (blue) that may play a role in regulated fusion of docked vesicles, where the components of the exocyst complex have been removed for clarity. Insulin promotes the release of Munc18c from syntaxin4 in a manner that may involve the phosphorylation of a tyrosine residue on Munc18c. Munc18c then binds Doc2 $\beta$, and the free syntaxin4 then interacts with VAMP2 and SNAP23 allowing vesicle fusion to proceed. Synip (not shown) may play a similar role to Munc18c. See text for more details.

plasma membrane liposomes, which allows the components of the assay to be manipulated separately. Importantly, the GLUT4 vesicles used in the assay represent 'basal' vesicles (GLUT4 is labelled at the cell surface and internalised prior to isolation) and therefore demonstrate that the GLUT4 vesicle itself does not require 'activation' by insulin for fusion to occur. Similarly, while the presence of the cytosol fraction is required for fusion to occur in vitro, insulin-stimulated plasma membrane liposomes can support vesicle fusion in the presence of 'basal cytosol'. Furthermore, insulin-activated cytosol is insufficient to facilitate the fusion of GLUT4 vesicles with plasma membrane liposomes prepared under basal conditions. Taken together, these observations strongly suggest that the insulin-regulated fraction is not the GLUT4 vesicle or the cytosol but the plasma membrane (Koumanov et al. 2005). While this study has provided some important insights into the regulation of GLUT4 vesicle fusion, it is important to recognise that this is an in vitro assay and therefore cannot provide any clues as to the degree to which this fusion step contributes to the overall translocation process.

The signalling pathway that regulates the docking and fusion of GLUT4 vesicles with the plasma membrane appears to be PI3K dependent. TIRF studies have demonstrated that in wortmannin-treated cells, stable docking events are almost completely absent and GLUT4 vesicle fusion is abolished (Bai et al. 2007). However, wortmannin has no significant effect on the density of GLUT4 vesicles within the TIRF zone suggesting that the movement of GLUT4 vesicles to the cell periphery is independent of PI3K signalling (Semiz et al. 2003, Bai et al. 2007). These findings are also in agreement with the in vitro fusion assay in which wortmannin is able to block fusion when added to the assay directly and when plasma membrane liposomes are prepared from wortmannintreated cells (Koumanov et al. 2005). Interestingly, no inhibition of fusion was observed when cytosol from wortmannin-treated cells was used in the assay indicating that the PI3K signal is not required to propagate beyond the plasma membrane for fusion to occur (Koumanov et al. 2005).

Several studies have now implicated the stimulation of $\mathrm{PKB} /$ Akt activity at the plasma membrane as the insulinsensitive step in signalling that ultimately leads to fusion. A partial inhibition in signalling using a low-temperature block that prevents the insulin-stimulated phosphorylation of $\mathrm{PKB} / \mathrm{Akt}$, but not the synthesis of $\mathrm{PIP}_{3}$, results in the accumulation of GLUT4 vesicles beneath the plasma membrane but an inhibition in fusion (van Dam et al. 2005). Whether the GLUT4 vesicles visible under the membrane in these experiments were formally in a 'docked' state was not investigated. A similar requirement for phosphorylated $\mathrm{PKB} / \mathrm{Akt}$ was also found for the in vitro fusion assay. Both the depletion of Akt1/2 from the cytosol and a reduction in $\mathrm{PKB} / \mathrm{Akt}$ phosphorylation by wortmannin following its recruitment to insulin-activated plasma membrane liposomes were found to significantly inhibit vesicle fusion (Koumanov et al. 2005). However, despite these studies, there remains some debate over the requirement of $\mathrm{PKB} / \mathrm{Akt}$ for fusion as the small molecule $\mathrm{PKB} / \mathrm{Akt}$ inhibitor Akti1/2 does not significantly reduce the fusion efficiency of docked GLUT4 vesicles within the TRIF zone and instead appears to inhibit the recruitment of GLUT4 to the cell surface (Gonzalez \& McGraw 2006).

TIRF studies have also enabled the inhibitory effect of the AS160 $_{4 \mathrm{P}}$ mutant on insulin-stimulated GLUT4 translocation to be studied in greater detail. In agreement with previous findings that the recruitment of GLUT4 vesicles to the cell membrane is PI3K independent, expression of the dominantnegative $\mathrm{AS} 160_{4 \mathrm{P}}$ mutant does not affect the vesicle density 
within the TIRF zone under basal or insulin-stimulated conditions (Bai et al. 2007). The phosphorylation mutant does, however, significantly reduce the docking rate of GLUT4 vesicles with the plasma membrane to below basal levels and as a result reduces fusion (Bai et al. 2007). However, for those vesicles that dock, the mutant does not reduce the fraction of fused versus docked vesicles in the presence of insulin indicating that AS160 is not involved in the control of fusion once vesicles become docked at the plasma membrane (Jiang et al. 2008). These observations, combined with the finding that the inhibitory effect of $\mathrm{AS} 160_{4} \mathrm{P}$ on insulinstimulated GLUT4 translocation is not maximal and can be reduced further using the Akti1/2 inhibitor (Gonzalez \& McGraw 2006), have led to the hypothesis that an alternative $\mathrm{PKB} /$ Akt substrate functions downstream of GLUT4 vesicle docking to control fusion.

As discussed above, the overall degree to which regulated docking and fusion contribute to net GLUT4 translocation to the plasma membrane, versus release of GLUT4 from sequestered stores, is not known. Under the static retention model, all three steps could potentially be involved. In the dynamic retention model, docking and fusion may be the most important regulated steps. The recent TIRF data are not necessarily consistent with the static retention model discussed above where GLUT4 vesicles are sequestered deep inside the cell within intracellular compartments that do not recycle with the plasma membrane. However, it should be noted that the results obtained by Bai et al. used replated 3T3L1 adipocytes where it has been argued that GLUT4 retention mechanism has been disrupted (Muretta et al. 2008). A further caveat in all studies using GFP-tagged GLUT4 chimeras is that the vesicles most relevant to the trafficking of GLUT4 (i.e. GSVs) may be difficult to visualise because they are small ( 50-60 nm diameter (Yu et al. 1999)) and so may possess insufficient numbers of GFP-tagged transporters to be readily observed by time-lapse fluorescence microscopy. It is therefore possible that the GLUT4containing vesicles observed within the TIRF zone are not GSVs but endosomes, which have been shown to contain up to $50 \%$ of the total GLUT4 pool.

\section{Protein complexes involved in docking and fusion of GLUT4 vesicles with the plasma membrane}

The docking and subsequent fusion of GLUT4 vesicles with the plasma membrane is likely to involve the formation of at least two key multiprotein complexes. A role for the exocyst, a complex of at least eight proteins, which plays a central role in the initial docking of exocytic vesicles in budding yeast, has now been shown to be a necessary component of the molecular machinery that facilitates enhanced glucose uptake via GLUT4 (see Fig. 4A (Inoue et al. 2003, Kanzaki \& Pessin 2003, Ewart et al. 2005, Inoue et al. 2006)). The exocyst components Exo70, sec6 and sec 8 are all proposed to be targeted to the same lipid rafts as GLUT4 in response to insulin and their siRNA-mediated depletion from cells inhibits insulin-stimulated glucose uptake by preventing the recruitment of GLUT4 to these plasma membrane domains (Inoue et al. 2006). In 3T3-L1 adipocytes, the expression of an Exo70 truncation mutant, which lacks the C-terminal domain, was found to inhibit insulin-stimulated glucose uptake but not GLUT4 translocation, as GLUT4 vesicles were seen to accumulate beneath the plasma membrane (Inoue et al. 2003). However, in primary rat adipose cells, expression of the same Exo70 mutant enhances GLUT4vesicle tethering in non-stimulated cells but did not induce fusion (Lizunov et al. 2009). Interestingly, the addition of insulin to cells expressing the Exo70 mutant stimulated the fusion of the apparently pre-tethered GLUT4 vesicles (Lizunov et al. 2009). Whether these different results arise from methodological or a cell-type specific difference is not known and warrants further investigation. Insulin has also been reported to stimulate the phosphorylation of sec8; however, this phosphorylation was not found to be necessary for insulin-stimulated GLUT4 vesicle fusion (Lyons et al. 2008).

The idea that the exocyst provides a 'docking platform' from which GLUT4 vesicles engage with the necessary fusion machinery in the plasma membrane is consistent with several TIRF studies where multiple GLUT4 vesicles are seen to traffic to and dock within specific areas of the plasma membrane where they subsequently undergo fusion (Lizunov et al. 2005). In primary adipocytes, these fusion sites appear as fluorescent 'hotspots' that gradually increase in size over the time course of insulin stimulation and in some cases merge with neighbouring sites (Lizunov et al. 2005). These fusion sites may, however, be sites of endocytosis as they have been shown to colocalise with clathrin (Huang et al. 2007). Huang et al. (2007) have therefore suggested that insulin stimulates the rate of transition between docking and fusion and promotes the transit of GLUT4 to sites of endocytosis within the plasma membrane in preparation for their internalisation following the termination of insulin signalling.

While the signalling events and molecular machinery responsible for exocyst recruitment to the plasma membrane remains to be determined, it is possible that the activation of the $\mathrm{TC} 10 / \mathrm{Cbl}$ pathway regulates the formation of the exocyst complex as Exo70 has been found to interact with TC10 at the plasma membrane (Fig. 4A; (Inoue et al. 2003)). In addition to TC10, the protein SAP97, which is a member of the family of membrane-associated guanylate kinase homologues (MAGUKs), has been identified as a sec8 interacting protein that localises to lipid rafts and is required for the recruitment of $\sec 8$, Exo70 and GLUT4 to these same lipid rafts (Inoue et al. 2006).

Following its recruitment to specific fusion sites, GLUT4 vesicles undergo facilitated fusion with the plasma membrane, a process that requires the $\mathrm{N}$-ethylmaleimide-sensitive factor (NSF) and its cofactor $\alpha$-SNAP, the membrane-bound SNARE proteins (soluble NSF receptors) as well as the Rab family of small GTPases (for a recent review on membrane 
fusion see (Wickner \& Schekman 2008)). The SNARE complex formed upon membrane contact involves the formation of a stable four-stranded coiled coil structure between the GLUT4 vesicle-associated SNARE protein, VAMP2, and the plasma-membrane localised SNAREs, syntaxin4 and SNAP23 (Olson et al. 1997, Martin et al. 1998, St-Denis et al. 1999, Kawanishi et al. 2000). The structure is thought to bring the two membranes close together in a manner that promotes the fusion of the lipid bilayers and its formation appears to be regulated by insulin through the association of various interacting proteins that either inhibit or facilitate SNARE complex assembly. One such protein is Munc18c, a syntaxin4-interacting protein, that functions as a negative regulator of SNARE complex formation by preventing the association of both SNAP23 and VAMP2 with syntaxin4 (Fig. 4B).

Insulin signalling leads to the dissociation of Munc18c from syntaxin4, which allows the SNARE complex to form and facilitate fusion (Araki et al. 1997, Tamori et al. 1998, Thurmond et al. 1998). This process has recently been shown to involve the insulin-stimulated phosphorylation of Munc18c on Tyr219, which is thought to induce a change in the binding specificity of Munc18c from syntaxin4 to Doc2 $\beta$ (Jewell et al. 2008), a double C2 domain-containing protein that has been identified as a positive regulator of exocytic vesicle fusion in both adipocytes and adrenal chromaffin cells (Ke et al. 2007, Friedrich et al. 2008, Sano et al. 2008, Fukuda et al. 2009). Other syntaxin4 binding proteins that appear to function as negative regulators of GLUT4 vesicle fusion include Synip (Min et al. 1999) and Tomosyn ((Widberg et al. 2003); these are not included in Fig. 4B for the sake of clarity). Like Munc18c, Synip interacts with syntaxin4 in an insulin-regulated manner and the disassembly of this complex is required for insulin-stimulated glucose uptake. Furthermore, as is the case for Munc18c, the phosphorylation of Synip may be responsible for the dissociation of Synip from syntaxin4 (Yamada et al. 2005). However, while one study has demonstrated that Ser99 is a substrate for $\mathrm{PKB} \beta$ and that mutation of this residue to phenylalanine inhibits the insulin-stimulated redistribution of GLUT4 to the plasma membrane (Yamada et al. 2005), a second study, in which Ser99 was mutated to alanine, failed to show the same inhibitory effect (Sano et al. 2005). Further studies have yet to be performed to establish whether phosphorylation plays a role in the regulation of the Synip-syntaxin4 interaction, therefore the mechanism through which this interaction is regulated by insulin remains controversial.

GLUT4 vesicle fusion with the plasma membrane also appears to be regulated by the Rab11-interacting protein, Rip11. Like several other proteins that are involved in fusion, including the exocyst components Exo70, sec6 and sec8, Rip11 is recruited to the plasma membrane by insulin. However, unlike the exocyst, Rip11 does partially colocalise with GLUT4 in the perinuclear region of 3T3-L1 adipocytes and displays identical trafficking properties to GLUT4/IRAP; however, it is not yet clear whether Rip11 is a component of GSVs (Welsh et al. 2007). The N-terminal C2 domain of Rip11, which has been shown to bind acidic phospholipids and the phosphoinositide $\mathrm{PIP}_{3}$ (Lindsay \& McCaffrey 2004), may play a role in targeting Rip11 to the plasma membrane in response to insulin. This raises the intriguing possibility that $\mathrm{PIP}_{3}$ may serve a dual function in insulin signalling, as a second messenger in the PI3K signal transduction pathway and as a receptor to recruit Rip11 to the cell surface where it is required for GLUT4 vesicle fusion. In addition to binding $\mathrm{PIP}_{3}$, Rip11 has also been shown to form a complex with AS160, which is thought to be present on GLUT4 vesicles, suggesting that Rip11 (Welsh et al. 2007), together with IRAP (Larance et al. 2005), may provide at least part of the molecular basis through which AS160 associates with GLUT4 vesicles in the absence of insulin (Fig. 4A). It remains to be determined whether Rip11 interacts with either the exocyst or SNARE machinery, although intriguingly it is known to interact with $\gamma$ SNAP (Tani et al. 2003).

Interestingly, both of the recently identified fusion regulators Doc2 $\beta$ and Rip11 contain C2 domains, a phospholipid binding domain that often requires $\mathrm{Ca}^{2+}$ to coordinate lipid binding. While the requirement of $\mathrm{Ca}^{2+}$ for Rip11 binding to acidic phospholipids has yet to be determined, in adrenal chromaffin cells, Doc $2 \beta$ is recruited to the cell surface in a $\mathrm{Ca}^{2+}$-dependent manner where it functions as a priming factor and increases the number of fusion-competent vesicles (Groffen et al. 2004, Friedrich et al. 2008). A recent study in 3T3-L1 adipocytes has demonstrated that Doc $2 \beta$ is recruited to the plasma membrane in an insulinand $\mathrm{Ca}^{2+}$-dependent manner where it associates with syntaxin4 (Fukuda et al. 2009). The recruitment of Doc2 $\beta$ was found to be necessary for GLUT4 vesicle fusion as both a mutant deficient in $\mathrm{Ca}^{2+}$ binding and the siRNA-mediated depletion of Doc $2 \beta$ from adipocytes inhibited insulinstimulated glucose uptake (Fukuda et al. 2009).

Although the late stages in insulin signalling share common features with neurotransmitter release, many studies have demonstrated that insulin signalling does not elicit changes in intracellular $\mathrm{Ca}^{2+}\left(\mathrm{Ca}^{2+}{ }_{[\mathrm{i}]}\right)$, which suggests that an increase in $\mathrm{Ca}^{2+}{ }_{[\mathrm{i}]}$ is unlikely to play a role in insulin-stimulated GLUT4 vesicle fusion and glucose uptake (Cheung et al. 1987, Klip \& Ramlal 1987, Kelly et al. 1989). However, it should be noted that one study has shown that while insulin does not alter global intracellular $\mathrm{Ca}^{2+}$ levels it does increase the concentration of free $\mathrm{Ca}^{2+}$ just beneath the plasma membrane of isolated mouse skeletal muscle fibres (Bruton et al. 2001). Several studies have also shown that the intracellular calcium chelator, BAPTA-AM, inhibits both insulin-stimulated GLUT4 translocation and glucose uptake (Whitehead et al. 2001, Worrall \& Olefsky 2002). However, while these studies with BAPTA-AM indicate that a minimal or permissive level of $\mathrm{Ca}^{2+}$ is required for insulin-stimulated glucose uptake they do not provide any evidence that insulin regulates $\mathrm{Ca}^{2+}{ }_{[i]}$ levels. Furthermore, while BAPTA-AM chelates $\mathrm{Ca}^{2+}$ ions with a 105-fold greater affinity than 
$\mathrm{Mg}^{2+}$, it avidly binds $\mathrm{Mn}^{2+}$, a divalent cation with many important biological functions. In addition to this, a recent study has demonstrated that BAPTA-AM treatment results in the profound depolymerisation of microtubules, which itself is known to cause the GLUT4 perinuclear compartment to become dispersed throughout the cytoplasm (Saoudi et al. 2004, Furuta et al. 2008). Importantly, these effects are independent of calcium chelation and suggest that BAPTAAM cannot be used exclusively to study the effects of calcium depletion in cells.

In a recent study, Yip et al. (2008) have found that insulin stimulates the phosphorylation of an unconventional Myo1c on a site that binds to 14-3-3 proteins, and which increases the ATPase activity of the Myo1c. Yip et al. propose a model whereby insulin promotes a rise in local $\mathrm{Ca}^{2+}$ concentration immediately underneath the plasma membrane via the activation of $\mathrm{a} \mathrm{Ca}^{2+}$ influx pathway. This might then stimulate Myo1c phosphorylation by the calmodulinregulated protein kinase, CaMKII, and so increase the ATPase activity of Myo1c. As Myo1c is responsible for actin-based motility, one plausible role for the protein is in accelerating the sliding motion of GLUT4 vesicles along cortical actin filaments that lie underneath the plasma membrane, allowing the vesicles to more rapidly and efficiently find hotspots with which to dock and fuse (step 3 in Fig. 3). This model requires considerable further testing, most especially whether $\mathrm{Ca}^{2+}$ plays a regulatory or permissive role.

\section{Therapeutic targets in the insulin signalling pathway}

The successful treatment of T1DM using purified insulin preparations in the early 1920s was a major breakthrough in medical science. The use of insulin analogues combined with frequent or even continuous glucose monitoring has significantly improved day-to-day control of glycaemia. However, a walk-away device that monitors plasma glucose and automatically adjusts insulin delivery accordingly is still some way off despite recent encouraging developments (Heller 2008, Tamborlane et al. 2008). Treatment of T2DM relies largely on the use of drugs that lower hepatic glucose output (metformin), stimulate insulin secretion (sulphonylureas) or improve insulin action via stimulation of the PPAR $\gamma$ transcription factor (glitazones). As these approaches are all either suboptimal or possess unwanted side effects, the development of orally available drugs that mimic insulin action remains an important goal for almost all of the major pharmaceutical companies. Such agents would have utility for the treatment of both T1DM and T2DM, although in the case of T1DM major pharmacodynamic issues would have to be resolved if an orally active insulin mimetic were to fully replace insulin injections (e.g. short and long acting analogues). In the case of the treatment of T2DM, an assumption must be made that the drug target is adequately expressed in the insulin-resistant target tissue.
While we do not yet have a full picture of the signalling pathway linking the insulin receptor to GLUT4 trafficking, in this section we will explore whether we are in a position to exploit any of the discoveries outlined in this review to develop improved drugs to treat T1DM and T2DM. We will not be discussing agents that lower plasma glucose by altering the activity of metabolic enzymes (e.g. glucokinase activators), nor will we cover GSK3 and protein phosphatase 1B inhibitors, as they appear to have lost favour in the industry for treatment of diabetes. Instead, the reader is directed to a number of recent and extensive reviews on these topics (Karylowski et al. 2004, Sarbassov et al. 2005, Cohen 2006, Zhang \& Zhang 2007).

A key therapeutic target is the insulin receptor itself as activation of this protein would mimic all the effects of insulin: i.e. among other things promote glucose uptake as well as its storage as glycogen and fat in muscle and fat tissues respectively, and inhibit glucose output by the liver through inhibition of gluconeogenesis. Targeting any other protein downstream of the insulin receptor would either i) not be selective (e.g. activation of IRS1/2 would mimic the action of insulin-like growth factor-1; activation of PI3-kinase and $\mathrm{PKB} /$ Akt would mimic the actions of numerous growth factors, cytokines and other hormones) or ii) would only mimic a subset of actions of insulin (e.g. inhibition of GSK3 would only stimulate glycogen synthesis; inhibition of AS160 would only be expected to stimulate glucose uptake with little significant stimulation of its storage). Targeting further downstream also comes with an increased risk for on-target side effects (e.g. the effect of GSK3 inhibitors on embryonic and adult development and neuronal function; the effect of $\mathrm{PKB} / \mathrm{Akt}$ activators on cell proliferation and survival).

Theoretically, mimicking insulin action could be brought about through drug-mediated activation of a positive regulator, or inhibition of a negative regulator, of insulin signalling. Many of the components of insulin signalling are protein kinases, and while this is an outstanding class of target for inhibitor development there are few examples of small molecule protein kinase activators. L-783 281 is one such example, being a tropical fungal metabolite that activates the insulin receptor probably via binding to the tyrosine kinase domain of the receptor (Zhang et al. 1999). Unfortunately, this compound appears to have direct actions on $\beta$-cell insulin secretion (Persaud et al. 2002, Roper et al. 2002), activates members of the Trk family of neurotrophic factor receptor tyrosine kinases (Wilkie et al. 2001) and possesses cellular toxicity (Wilkie et al. 2001). Such on- and off-target toxicity has almost certainly hampered attempts to move this compound out of the laboratory and into the clinic. However, it provides proof-of-principle for an important approach to drug development.

Given the difficulties in delivering an insulin receptor agonist to the clinic, exploring targets downstream of the insulin receptor becomes particularly valid even given their less than optimal likely actions on whole-body glucose homeostasis. 
As a suppressor of insulin-stimulated glucose uptake, the AS160 Rab-GAP maintains its target Rab in the inactive GDP-bound state and insulin is proposed to inhibit the GAP activity of AS160. Targeting the GAP activity of AS160 therapeutically is, therefore, predicated on this as yet unproven hypothesis; although as siRNA-mediated knockdown of AS160 expression stimulates basal glucose uptake, it appears likely that insulin either inhibits AS160 activity or at least restricts its access to its substrate Rab. Assuming this to be the case, any compound that inhibited the GAP activity of AS160 would be expected to activate the target Rab by promoting its transition to the GTP-bound state. This would stimulate basal glucose uptake in the absence of insulin, as observed with siRNA-mediated knockdown of AS160 (Eguez et al. 2005, Larance et al. 2005). Unfortunately, the molecular mechanism by which GAP proteins stimulate the GTPase activity intrinsic to their target $\mathrm{Rab}$ is highly complex; the GAP contributes a critical arginine residue (or finger) into the active site of the Rab GTPase, stabilising the transition state of the GTPase reaction (Scheffzek et al. 1997, Kawanishi et al. 2000). This not only makes configuring a high-throughput screen for the AS160-Rab interaction very complex, but also means that absolute certainty in knowing the physiologically relevant Rab(s) for the AS160 GAP domain is an imperative. Given the possible role for AS160 in insulin secretion by the $\beta$-cell (Bouzakri \& Zierath 2007), and the high expression of AS160 in the hypothalamus and so possible role in appetite control, understanding the role of this widely expressed protein in other tissue systems is also an imperative for assessing potential on-target side effects of AS160-GAP inhibitors.

An alternative approach is to block the targeting of AS160 to GLUT4 vesicles, an approach that may be more tissue selective. As discussed above, AS160 binds to both IRAP and Rip11, but it remains to be established whether these are mutually exclusive interactions. In both cases, insulin reduces the interaction and this could, by inference, lead to the dissociation of AS160 from the GLUT4 vesicle and so activation of the target $\mathrm{Rab}$ that is assumed to remain on the vesicle. Small molecule inhibitors of the AS160:Rip11 or AS160:IRAP interactions could increase the activity of the target Rab. An advantage here would be that the identity of the target Rab does not need to be known to run a highthroughput screen. Clearly, however, a considerable amount of additional detail concerning these two interactions and their underlying contribution to the stimulation of glucose uptake is required before embarking on a major screening programme. In addition, protein:protein interactions have proven considerably more elusive to target with small molecule inhibitors as they tend to involve relatively large areas of the surface of the two proteins. However, potent protein:protein interaction inhibitors have been successfully developed (Berg 2008).

Another potential target for therapeutic intervention is the interaction between syntaxin 4 and Munc18c (or, alternatively, Synip). The syntaxin4:Munc18c interaction has been reported to be inhibited by insulin (Thurmond et al. 1998) and a polyclonal Munc18c antibody stimulates basal GLUT4 translocation when microinjected into 3T3-L1 adipocytes (Macaulay et al. 2002). However, several observations make it difficult to ascertain whether this interaction positively or negatively regulates GLUT4 translocation and/or fusion. First, a peptide that blocks the syntaxin 4 interaction with Munc18c inhibits insulin-stimulated GLUT4 translocation (Thurmond et al. 2000). Secondly, the effect of a knockout of Munc18c in mice has different effects depending on the experimental approach used by the two groups to phenotype the manipulation, a consequence of the embryonic lethality of a homozygous knockout. On the one hand, Thurmond et al. generated Munc18c-/+ heterozygous mice that displayed insulin resistance and reduced GLUT4 translocation in muscle (Oh et al. 2005). On the other, Kanda et al. (2005) studied differentiated adipocytes artificially derived from MEFs isolated from homozygous Munc18c-/- mouse embryos. These displayed enhanced insulin-stimulated GLUT4 exposure at the cell surface, but exposure in the basal state was unaffected. Some of these controversies and difficulties may be explained by the fact that Munc18c contains two binding sites for syntaxin 4 , one being disrupted by insulin while the other is activated by insulin (Smithers et al. 2008). Clearly, we need to understand much more about the syntain4:Munc18c interaction (or syntaxin4:Synip) before considering it a validated therapeutic target, although it has some attractions given its relatively selective role in GLUT4 trafficking. However, it should be noted that Munc18c also plays a role in pancreatic $\beta$-cell insulin granule exocytosis (Oh \& Thurmond 2006).

\section{Summary}

While we have made extraordinary progress in understanding how insulin stimulates glucose uptake, most especially with respect to the insulin signalling and vesicle fusion machinery involved, uncovering targets for therapeutic intervention has yet to yield any orally available insulin mimics that have progressed beyond testing in animal model systems. However, given the inexorable rise in incidence of both T1DM and T2DM, and the rate at which our knowledge of insulinregulated glucose transport is advancing, we have over the next 10-15 years some real potential to yield the Holy Grail of diabetes research, orally available insulin mimetics.

\section{Declaration of interest}

The authors declare that there is no conflict of interest that could be perceived as prejudicing the impartiality of the research reported.

\section{Funding}

Work in the authors' laboratory is funded by the Medical Research Council, Diabetes UK, AstraZeneca and (OSI) Prosidion. 


\section{Acknowledgements}

We thank Dick Denton (University of Bristol) for useful discussions.

\section{References}

Alessi DR, James SR, Downes CP, Holmes AB, Gaffney PR, Reese CB \& Cohen P 1997 Characterization of a 3-phosphoinositide-dependent protein kinase which phosphorylates and activates protein kinase Balpha. Current Biology 7 261-269.

Andjelkovic M, Alessi DR, Meier R, Fernandez A, Lamb NJ, Frech M, Cron P, Cohen P, Lucocq JM \& Hemmings BA 1997 Role of translocation in the activation and function of protein kinase $\mathrm{B}$ Journal of Biological Chemistry 272 31515-31524.

Araki S, Tamori Y, Kawanishi M, Shinoda H, Masugi J, Mori H, Niki T, Okazawa H, Kubota T \& Kasuga M 1997 Inhibition of the binding of SNAP-23 to syntaxin 4 by Munc18c. Biochemical and Biophysical Research Communications 234 257-262.

Bai L, Wang Y, Fan J, Chen Y, Ji W, Qu A, Xu P, James DE \& Xu T 2007 Dissecting multiple steps of GLUT4 trafficking and identifying the sites of insulin action. Cell Metabolism 5 47-57.

Bandyopadhyay G, Standaert ML, Galloway L, Moscat J \& Farese RV 1997 a Evidence for involvement of protein kinase C (PKC)-zeta and noninvolvement of diacylglycerol-sensitive PKCs in insulin-stimulated glucose transport in L6 myotubes. Endocrinology 138 4721-4731.

Bandyopadhyay G, Standaert ML, Zhao L, Yu B, Avignon A, Galloway L, Karnam P, Moscat J \& Farese RV 1997 b Activation of protein kinase C (alpha, beta, and zeta) by insulin in 3T3/L1 cells. Transfection studies suggest a role for PKC-zeta in glucose transport. Journal of Biological Chemistry 272 2551-2558.

Berg T 2008 Small-molecule inhibitors of protein-protein interactions. Current Opinion in Drug Discovery \& Development 11 666-674.

Berwick DC, Dell GC, Welsh GI, Heesom KJ, Hers I, Fletcher LM, Cooke FT \& Tavare JM 2004 Protein kinase B phosphorylation of PIKfyve regulates the trafficking of GLUT4 vesicles. Journal of Cell Science 117 5985-5993.

Birnbaum MJ 1989 Identification of a novel gene encoding an insulinresponsive glucose transporter protein. Cell 57 305-315.

Bogan JS, Hendon N, McKee AE, Tsao TS \& Lodish HF 2003 Functional cloning of TUG as a regulator of GLUT4 glucose transporter trafficking. Nature 425 727-733.

Bornemann A, Ploug T \& Schmalbruch H 1992 Subcellular localization of GLUT4 in nonstimulated and insulin-stimulated soleus muscle of rat. Diabetes 41 215-221.

Bouzakri K \& Zierath JR 2007 MAP4K4 gene silencing in human skeletal muscle prevents tumor necrosis factor-alpha-induced insulin resistance. Journal of Biological Chemistry 282 7783-7789.

Bruton JD, Katz A \& Westerblad H 2001 The role of $\mathrm{Ca}^{2+}$ and calmodulin in insulin signalling in mammalian skeletal muscle. Acta Physiologica Scandinavia 171 259-265.

Calderhead DM, Kitagawa K, Tanner LI, Holman GD \& Lienhard GE 1990 Insulin regulation of the two glucose transporters in 3T3-L1 adipocytes. Journal of Biological Chemistry 265 13801-13808.

Chadt A, Leicht K, Deshmukh A, Jiang LQ, Scherneck S, Bernhardt U, Dreja T, Vogel H, Schmolz K, Kluge R et al. 2008 Tbc1d1 mutation in lean mouse strain confers leanness and protects from diet-induced obesity. Nature Genetics 40 1354-1359.

Chang L, Adams RD \& Saltiel AR 2002 The TC10-interacting protein CIP4/2 is required for insulin-stimulated Glut4 translocation in 3T3L1 adipocytes. PNAS 99 12835-12840.

Chang L, Chiang SH \& Saltiel AR 2007 TC10alpha is required for insulin-stimulated glucose uptake in adipocytes. Endocrinology 148 27-33.

Charron MJ, Brosius FC III, Alper SL \& Lodish HF 1989 A glucose transport protein expressed predominately in insulin-responsive tissues. PNAS $\mathbf{8 6}$ 2535-2539.
Chen X, Al-Hasani H, Olausson T, Wenthzel AM, Smith U \& Cushman SW 2003 Activity, phosphorylation state and subcellular distribution of GLUT4-targeted Akt2 in rat adipose cells. Journal of Cell Science 116 3511-3518.

Cheung JY, Constantine JM \& Bonventre JV 1987 Cytosolic free calcium concentration and glucose transport in isolated cardiac myocytes. American Journal of Physiology 252 C163-C172.

Cho H, Mu J, Kim JK, Thorvaldsen JL, Chu Q, Crenshaw EB III, Kaestner KH, Bartolomei MS, Shulman GI \& Birnbaum MJ 2001 Insulin resistance and a diabetes mellitus-like syndrome in mice lacking the protein kinase Akt2 (PKB beta). Science 292 1728-1731.

Civera C, Simon B, Stier G, Sattler M \& Macias MJ 2005 Structure and dynamics of the human pleckstrin DEP domain: distinct molecular features of a novel DEP domain subfamily. Proteins 58 354-366.

Cohen P 2006 The twentieth century struggle to decipher insulin signalling. Nature Reviews. Molecular Cell Biology 7 867-873.

Cong LN, Chen H, Li Y, Zhou L, McGibbon MA, Taylor SI \& Quon MJ 1997 Physiological role of Akt in insulin-stimulated translocation of GLUT4 in transfected rat adipose cells. Molecular Endocrinology 11 1881-1890.

Cushman SW \& Wardzala LJ 1980 Potential mechanism of insulin action on glucose transport in the isolated rat adipose cell. Apparent translocation of intracellular transport systems to the plasma membrane. Journal of Biological Chemistry 255 4758-4762.

Czech MP, Chawla A, Woon CW, Buxton J, Armoni M, Tang W, Joly M \& Corvera S 1993 Exofacial epitope-tagged glucose transporter chimeras reveal COOH-terminal sequences governing cellular localization. Journal of Cell Biology 123 127-135.

van Dam EM, Govers R \& James DE 2005 Akt activation is required at a late stage of insulin-induced GLUT4 translocation to the plasma membrane. Molecular Endocrinology 19 1067-1077.

Dawson K, Aviles-Hernandez A, Cushman SW \& Malide D 2001 Insulinregulated trafficking of dual-labeled glucose transporter 4 in primary rat adipose cells. Biochemical and Biophysical Research Communications 287 445-454.

Deems RO, Deacon RW, Ramlal T, Volchuk A, Klip A \& Young DA 1994 Insulin action on whole body glucose utilization and on muscle glucose transporter translocation in mice. Biochemical and Biophysical Research Communications 199 662-670.

Dobson SP, Livingstone C, Gould GW \& Tavare JM 1996 Dynamics of insulin-stimulated translocation of GLUT4 in single living cells visualised using green fluorescent protein. FEBS Letters 393 179-184.

Ducluzeau PH, Fletcher LM, Welsh GI \& Tavare JM 2002 Functional consequence of targeting protein kinase B/Akt to GLUT4 vesicles. Journal of Cell Science 115 2857-2866.

Dummler B, Tschopp O, Hynx D, Yang ZZ, Dirnhofer S \& Hemmings BA 2006 Life with a single isoform of Akt: mice lacking Akt2 and Akt3 are viable but display impaired glucose homeostasis and growth deficiencies. Molecular and Cellular Biology 26 8042-8051.

Eguez L, Lee A, Chavez JA, Miinea CP, Kane S, Lienhard GE \& McGraw TE 2005 Full intracellular retention of GLUT4 requires AS160 Rab GTPase activating protein. Cell Metabolism 2 263-272.

Ewart MA, Clarke M, Kane S, Chamberlain LH \& Gould GW 2005 Evidence for a role of the exocyst in insulin-stimulated Glut4 trafficking in 3T3-L1 adipocytes. Journal of Biological Chemistry 280 3812-3816.

Fletcher LM, Welsh GI, Oatey PB \& Tavare JM 2000 Role for the microtubule cytoskeleton in GLUT4 vesicle trafficking and in the regulation of insulin-stimulated glucose uptake. Biochemical Journal 352 267-276.

Friedman JE, Dudek RW, Whitehead DS, Downes DL, Frisell WR, Caro JF \& Dohm GL 1991 Immunolocalization of glucose transporter GLUT4 within human skeletal muscle. Diabetes 40 150-154

Friedrich R, Groffen AJ, Connell E, van Weering JR, Gutman O, Henis YI, Davletov B \& Ashery U 2008 DOC2B acts as a calcium switch and enhances vesicle fusion. Journal of Neuroscience 28 6794-6806. 
Fukuda N, Emoto M, Nakamori Y, Taguchi A, Miyamoto S, Uraki S, Oka Y \& Tanizawa Y 2009 DOC2B: a novel syntaxin-4 binding protein mediating insulin-regulated GLUT4 vesicle fusion in adipocytes. Diabetes 58 377-384.

Fukumoto H, Kayano T, Buse JB, Edwards Y, Pilch PF, Bell GI \& Seino S 1989 Cloning and characterization of the major insulin-responsive glucose transporter expressed in human skeletal muscle and other insulin-responsive tissues. Journal of Biological Chemistry 264 7776-7779.

Furuta A, Tanaka M, Omata W, Nagasawa M, Kojima I \& Shibata H 2008 Microtubule disruption with BAPTA and dimethyl BAPTA by a calcium chelation-independent mechanism in 3T3-L1 adipocytes. Endocrine Journal $56235-243$.

Garofalo RS, Orena SJ, Rafidi K, Torchia AJ, Stock JL, Hildebrandt AL, Coskran T, Black SC, Brees DJ, Wicks JR et al. 2003 Severe diabetes, age-dependent loss of adipose tissue, and mild growth deficiency in mice lacking Akt2/PKB beta. Journal of Clinical Investigation 112 197-208.

Geraghty K, Chen S, Harthill JE, Ibrahim AF, Toth R, Morrice NA, Vandermoere F, Moorhead GB, Hardie DG \& Mackintosh C 2007 Regulation of multisite phosphorylation and 14-3-3 binding of AS160 in response to insulin-like growth factor 1, EGF, PMA and AICAR. Biochemical Journal 407 231-241.

Gonzalez E \& McGraw TE 2006 Insulin signaling diverges into Aktdependent and -independent signals to regulate the recruitment/docking and the fusion of GLUT4 vesicles to the plasma membrane. Molecular Biology of the Cell 17 4484-4493.

Govers R, Coster AC \& James DE 2004 Insulin increases cell surface GLUT4 levels by dose dependently discharging GLUT4 into a cell surface recycling pathway. Molecular and Cellular Biology 24 6456-6466.

Green CJ, Goransson O, Kular GS, Leslie NR, Gray A, Alessi DR, Sakamoto K \& Hundal HS 2008 Use of Akt inhibitor and a drug-resistant mutant validates a critical role for protein kinase $\mathrm{B} / \mathrm{Akt}$ in the insulin-dependent regulation of glucose and system A amino acid uptake. Journal of Biological Chemistry 283 27653-27667.

Groffen AJ, Brian EC, Dudok JJ, Kampmeijer J, Toonen RF \& Verhage M $2004 \mathrm{Ca}(2+)$-induced recruitment of the secretory vesicle protein DOC2B to the target membrane. Journal of Biological Chemistry 279 23740-23747.

Guilherme A, Soriano NA, Furcinitti PS \& Czech MP 2004 Role of EHD1 and EHBP1 in perinuclear sorting and insulin-regulated GLUT4 recycling in 3T3-L1 adipocytes. Journal of Biological Chemistry 279 40062-40075.

Hanpeter D \& James DE 1995 Characterization of the intracellular GLUT-4 compartment. Molecular Membrane Biology 12 263-269.

Heller SR 2008 Minimizing hypoglycemia while maintaining glycemic control in diabetes. Diabetes $\mathbf{5 7}$ 3177-3183.

Hill MM, Clark SF, Tucker DF, Birnbaum MJ, James DE \& Macaulay SL 1999 A role for protein kinase Bbeta/Akt2 in insulin-stimulated GLUT4 translocation in adipocytes. Molecular and Cellular Biology 19 7771-7781.

Holman GD, Kozka IJ, Clark AE, Flower CJ, Saltis J, Habberfield AD, Simpson IA \& Cushman SW 1990 Cell surface labeling of glucose transporter isoform GLUT4 by bis-mannose photolabel. Correlation with stimulation of glucose transport in rat adipose cells by insulin and phorbol ester. Journal of Biological Chemistry 265 18172-18179.

Hou JC \& Pessin JE 2007 Ins (endocytosis) and outs (exocytosis) of GLUT4 trafficking. Current Opinion in Cell Biology 19 466-473.

Hresko RC \& Mueckler M 2005 mTOR.RICTOR is the Ser473 kinase for Akt/protein kinase B in 3T3-L1 adipocytes. Journal of Biological Chemistry 280 40406-40416.

Huang S, Lifshitz LM, Jones C, Bellve KD, Standley C, Fonseca S, Corvera S, Fogarty KE \& Czech MP 2007 Insulin stimulates membrane fusion and GLUT4 accumulation in clathrin coats on adipocyte plasma membranes. Molecular and Cellular Biology 27 3456-3469.

Ikonomov OC, Sbrissa D, Mlak K \& Shisheva A 2002 Requirement for PIKfyve enzymatic activity in acute and long-term insulin cellular effects. Endocrinology 143 4742-4754.

Ikonomov OC, Sbrissa D, Dondapati R \& Shisheva A 2007 ArPIKfyvePIKfyve interaction and role in insulin-regulated GLUT4 translocation and glucose transport in 3T3-L1 adipocytes. Experimental Cell Research 313 2404-2416.
Imamura T, Huang J, Usui I, Satoh H, Bever J \& Olefsky JM 2003 Insulin-induced GLUT4 translocation involves protein kinase C-lambdamediated functional coupling between Rab4 and the motor protein kinesin. Molecular and Cellular Biology 23 4892-4900.

Inoue M, Chang L, Hwang J, Chiang SH \& Saltiel AR 2003 The exocyst complex is required for targeting of Glut 4 to the plasma membrane by insulin. Nature 422 629-633.

Inoue M, Chiang SH, Chang L, Chen XW \& Saltiel AR 2006 Compartmentalization of the exocyst complex in lipid rafts controls Glut4 vesicle tethering. Molecular Biology of the Cell 17 2303-2311.

Ishikura S, Bilan PJ \& Klip A 2007 Rabs 8A and 14 are targets of the insulinregulated Rab-GAP AS160 regulating GLUT4 traffic in muscle cells. Biochemical and Biophysical Research Communications 353 1074-1079.

Ishikura S, Koshkina A \& Klip A 2008 Small G proteins in insulin action: Rab and Rho families at the crossroads of signal transduction and GLUT4 vesicle traffic. Acta Physiologica 192 61-74.

James DE, Strube M \& Mueckler M 1989 Molecular cloning and characterization of an insulin-regulatable glucose transporter. Nature 338 83-87.

JeBailey L, Rudich A, Huang X, Di Ciano-Oliveira C, Kapus A \& Klip A 2004 Skeletal muscle cells and adipocytes differ in their reliance on TC10 and Rac for insulin-induced actin remodeling. Molecular Endocrinology 18 359-372.

Jefferies HB, Cooke FT, Jat P, Boucheron C, Koizumi T, Hayakawa M, Kaizawa H, Ohishi T, Workman P, Waterfield MD et al. 2008 A selective PIKfyve inhibitor blocks PtdIns $(3,5) \mathrm{P}(2)$ production and disrupts endomembrane transport and retroviral budding. EMBO Reports 9 164-170.

Jewell JL, Oh E, Bennett SM, Meroueh SO \& Thurmond DC 2008 The tyrosine phosphorylation of Munc18c induces a switch in binding specificity from syntaxin 4 to Doc2beta. Journal of Biological Chemistry $28321734-21746$.

Jiang ZY, Chawla A, Bose A, Way M \& Czech MP 2002 A phosphatidylinositol 3-kinase-independent insulin signaling pathway to N-WASP/Arp2/3/F-actin required for GLUT4 glucose transporter recycling. Journal of Biological Chemistry 277 509-515.

Jiang L, Fan J, Bai L, Wang Y, Chen Y, Yang L, Chen L \& Xu T 2008 Direct quantification of fusion rate reveals a distal role forAS160 in insulinstimulated fusion of GLUT4 storage vesicles. Journal of Biological Chemistry 283 8508-8516.

Kaddai V, Le Marchand-Brustel Y \& Cormont M 2008 Rab proteins in endocytosis and Glut4 trafficking. Acta Physiologica 192 75-88.

Kaestner KH, Christy RJ, McLenithan JC, Braiterman LT, Cornelius P, Pekala PH \& Lane MD 1989 Sequence, tissue distribution, and differential expression of mRNA for a putative insulin-responsive glucose transporter in mouse 3T3-L1 adipocytes. PNAS 86 3150-3154.

Kanai F, Nishioka Y, Hayashi H, Kamohara S, Todaka M \& Ebina Y 1993 Direct demonstration of insulin-induced GLUT4 translocation to the surface of intact cells by insertion of a c-myc epitope into an exofacial GLUT4 domain. Journal of Biological Chemistry 268 14523-14526.

Kanda H, Tamori Y, Shinoda H, Yoshikawa M, Sakaue M, Udagawa J, Otani H, Tashiro F, Miyazaki J \& Kasuga M 2005 Adipocytes from Munc18c-null mice show increased sensitivity to insulin-stimulated GLUT4 externalization. Journal of Clinical Investigation 115 291-301.

Kandror K \& Pilch PF 1994a Identification and isolation of glycoproteins that translocate to the cell surface from GLUT4-enriched vesicles in an insulindependent fashion. Journal of Biological Chemistry 269 138-142.

Kandror KV \& Pilch PF $1994 b$ gp160, a tissue-specific marker for insulinactivated glucose transport. PNAS 91 8017-8021.

Kandror KV \& Pilch PF 1996 The insulin-like growth factor II/mannose 6-phosphate receptor utilizes the same membrane compartments as GLUT4 for insulin-dependent trafficking to and from the rat adipocyte cell surface. Journal of Biological Chemistry 271 21703-21708.

Kane S, Sano H, Liu SC, Asara JM, Lane WS, Garner CC \& Lienhard GE 2002 A method to identify serine kinase substrates. Akt phosphorylates a novel adipocyte protein with a Rab GTPase-activating protein (GAP) domain. Journal of Biological Chemistry 277 22115-22118. 
Kanzaki M \& Pessin JE 2001 Insulin-stimulated GLUT4 translocation in adipocytes is dependent upon cortical actin remodeling. Journal of Biological Chemistry 276 42436-42444.

Kanzaki M \& Pessin JE 2003 Insulin signaling: GLUT4 vesicles exit via the exocyst. Current Biology 13 R574-R576.

Karylowski O, Zeigerer A, Cohen A \& McGraw TE 2004 GLUT4 is retained by an intracellular cycle of vesicle formation and fusion with endosomes. Molecular Biology of the Cell 15 870-882.

Katome T, Obata T, Matsushima R, Masuyama N, Cantley LC, Gotoh Y, Kishi K, Shiota H \& Ebina Y 2003 Use of RNA interference-mediated gene silencing and adenoviral overexpression to elucidate the roles of $\mathrm{AKT} /$ protein kinase B isoforms in insulin actions. Journal of Biological Chemistry 278 28312-28323.

Kawanishi M, Tamori Y, Okazawa H, Araki S, Shinoda H \& Kasuga M 2000 Role of SNAP23 in insulin-induced translocation of GLUT4 in 3T3-L1 adipocytes. Mediation of complex formation between syntaxin 4 and VAMP2. Journal of Biological Chemistry 275 8240-8247.

$\mathrm{Ke} \mathrm{B}$, Oh E \& Thurmond DC 2007 Doc2beta is a novel Munc18c-interacting partner and positive effector of syntaxin 4-mediated exocytosis. Journal of Biological Chemistry 282 21786-21797.

Keller SR, Scott HM, Mastick CC, Aebersold R \& Lienhard GE 1995 Cloning and characterization of a novel insulin-regulated membrane aminopeptidase from Glut4 vesicles. Journal of Biological Chemistry $27023612-23618$.

Kelly KL, Deeney JT \& Corkey BE 1989 Cytosolic free calcium in adipocytes. Distinct mechanisms of regulation and effects on insulin action. Journal of Biological Chemistry 264 12754-12757.

Klip A \& Ramlal T 1987 Cytoplasmic $\mathrm{Ca}^{2+}$ during differentiation of 3T3-L1 adipocytes. Effect of insulin and relation to glucose transport. Journal of Biological Chemistry 262 9141-9146.

Kohn AD, Summers SA, Birnbaum MJ \& Roth RA 1996 Expression of a constitutively active Akt Ser/Thr kinase in 3T3-L1 adipocytes stimulates glucose uptake and glucose transporter 4 translocation. Journal of Biological Chemistry 271 31372-31378.

Koumanov F, Jin B, Yang J \& Holman GD 2005 Insulin signaling meets vesicle traffic of GLUT4 at a plasma-membrane-activated fusion step. Cell Metabolism 2 179-189.

Larance M, Ramm G, Stockli J, van Dam EM, Winata S, Wasinger V, Simpson F, Graham M, Junutula JR, Guilhaus M et al. 2005 Characterization of the role of the Rab GTPase-activating protein AS160 in insulin-regulated GLUT4 trafficking. Journal of Biological Chemistry $28037803-37813$.

Lauritzen HP, Ploug T, Ai H, Donsmark M, Prats C \& Galbo H 2008 Denervation and high-fat diet reduce insulin signaling in T-tubules in skeletal muscle of living mice. Diabetes 57 13-23.

Levine R \& Goldstein MS 1958 On the mechanism of action of insulin. Hormoner 11 2-22.

Lindsay AJ \& McCaffrey MW 2004 The C2 domains of the class I Rab11 family of interacting proteins target recycling vesicles to the plasma membrane. Journal of Cell Science 117 4365-4375.

Liu LZ, He AB, Liu XJ, Li Y, Chang YS \& Fang FD 2006 Protein kinase Czeta and glucose uptake. Biochemistry 71 701-706.

Liu LB, Omata W, Kojima I \& Shibata H 2007 The SUMO conjugating enzyme $\mathrm{Ubc} 9$ is a regulator of GLUT4 turnover and targeting to the insulin-responsive storage compartment in 3T3-L1 adipocytes. Diabetes 56 1977-1985.

Lizunov VA, Matsumoto H, Zimmerberg J, Cushman SW \& Frolov VA 2005 Insulin stimulates the halting, tethering, and fusion of mobile GLUT4 vesicles in rat adipose cells. Journal of Cell Biology 169 481-489.

Lizunov VA, Lisinski I, Stenkula K, Zimmerberg J \& Cushman SW 2009 Insulin regulates fusion of GLUT4 vesicles independent of Exo70-mediated tethering. Journal of Biological Chemistry 284 7914-7919.

Lodhi IJ, Chiang SH, Chang L, Vollenweider D, Watson RT, Inoue M, Pessin JE \& Saltiel AR 2007 Gapex-5, a Rab31 guanine nucleotide exchange factor that regulates Glut4 trafficking in adipocytes. Cell Metabolism 5 59-72.

Lorenzo M, Teruel T, Hernandez R, Kayali AG \& Webster NJ 2002 PLCgamma participates in insulin stimulation of glucose uptake through activation of PKCzeta in brown adipocytes. Experimental Cell Research 278 146-157.
Lyons PD, Peck GR, Kettenbach AN, Gerber SA, Roudaia L \& Lienhard GE 2008 Insulin stimulates the phosphorylation of the exocyst protein Sec8 in adipocytes. Bioscience Reports 29 229-235.

Macaulay SL, Grusovin J, Stoichevska V, Ryan JM, Castelli LA \& Ward CW 2002 Cellular munc18c levels can modulate glucose transport rate and GLUT4 translocation in 3T3L1 cells. FEBS Letters 528 154-160.

Maffucci T, Brancaccio A, Piccolo E, Stein RC \& Falasca M 2003 Insulin induces phosphatidylinositol-3-phosphate formation through TC10 activation. EMBO Journal 22 4178-4189.

Malide D, Dwyer NK, Blanchette-Mackie EJ \& Cushman SW 1997 Immunocytochemical evidence that GLUT4 resides in a specialized translocation post-endosomal VAMP2-positive compartment in rat adipose cells in the absence of insulin. Journal of Histochemistry and Cytochemistry 45 1083-1096.

Marette A, Burdett E, Douen A, Vranic M \& Klip A 1992 Insulin induces the translocation of GLUT4 from a unique intracellular organelle to transverse tubules in rat skeletal muscle. Diabetes 41 1562-1569.

Mari M, Monzo P, Kaddai V, Keslair F, Gonzalez T, Le Marchand-Brustel Y \& Cormont M 2006 The Rab4 effector Rabip4 plays a role in the endocytotic trafficking of Glut 4 in 3T3-L1 adipocytes. Journal of Cell Science 119 1297-1306.

Martin LB, Shewan A, Millar CA, Gould GW \& James DE 1998 Vesicleassociated membrane protein 2 plays a specific role in the insulin-dependent trafficking of the facilitative glucose transporter GLUT4 in 3T3-L1 adipocytes. Journal of Biological Chemistry 273 1444-1452.

Martin OJ, Lee A \& McGraw TE 2006 GLUT4 distribution between the plasma membrane and the intracellular compartments is maintained by an insulin-modulated bipartite dynamic mechanism. Journal of Biological Chemistry 281 484-490.

Meyre D, Farge M, Lecoeur C, Proenca C, Durand E, Allegaert F, Tichet J, Marre M, Balkau B, Weill J et al. 2008 R125W coding variant in TBC1D1 confers risk for familial obesity and contributes to linkage on chromosome 4p14 in the French population. Human Molecular Genetics 17 1798-1802.

Miinea CP, Sano H, Kane S, Sano E, Fukuda M, Peranen J, Lane WS \& Lienhard GE 2005 AS160 the Akt substrate regulating GLUT4 translocation, has a functional Rab GTPase-activating protein domain. Biochemical Journal 391 87-93.

Min J, Okada S, Kanzaki M, Elmendorf JS, Coker KJ, Ceresa BP, Syu LJ, Noda Y, Saltiel AR \& Pessin JE 1999 Synip: a novel insulin-regulated syntaxin 4-binding protein mediating GLUT4 translocation in adipocytes. Molecular Cell 3 751-760.

Minami A, Iseki M, Kishi K, Wang M, Ogura M, Furukawa N, Hayashi S, Yamada M, Obata T, Takeshita Y et al. 2003 Increased insulin sensitivity and hypoinsulinemia in APS knockout mice. Diabetes 52 2657-2665.

Mitra P, Zheng X \& Czech MP 2004 RNAi-based analysis of CAP, Cbl, and CrkII function in the regulation of GLUT4 by insulin. Journal of Biological Chemistry 279 37431-37435.

Molero JC, Whitehead JP, Meerloo T \& James DE 2001 Nocodazole inhibits insulin-stimulated glucose transport in 3T3-L1 adipocytes via a microtubule-independent mechanism. Journal of Biological Chemistry 276 43829-43835.

Molero JC, Jensen TE, Wthers PC, Couzens M, Herzog H, Thien CB, Langdon WY, Walder K, Murphy MA, Bowtell DD et al. 2004 c-Cbldeficient mice have reduced adiposity, higher energy expenditure, and improved peripheral insulin action. Journal of Clinical Investigation $\mathbf{1 1 4}$ 1326-1333.

Muretta JM, Romenskaia I \& Mastick CC 2008 Insulin releases Glut4 from static storage compartments into cycling endosomes and increases the rate constant for Glut4 exocytosis. Journal of Biological Chemistry 283 311-323.

$\mathrm{Ng}$ Y, Ramm G, Lopez JA \& James DE 2008 Rapid activation of Akt2 is sufficient to stimulate GLUT4 translocation in 3T3-L1 adipocytes. Cell Metabolism 7 348-356.

Oh E \& Thurmond DC 2006 The stimulus-induced tyrosine phosphorylation of Munc18c facilitates vesicle exocytosis. Journal of Biological Chemistry 281 17624-17634. 
Oh E, Spurlin BA, Pessin JE \& Thurmond DC 2005 Munc18c heterozygous knockout mice display increased susceptibility for severe glucose intolerance. Diabetes 54 638-647.

Olson AL, Knight JB \& Pessin JE 1997 Syntaxin 4, VAMP2, and/or VAMP3/cellubrevin are functional target membrane and vesicle SNAP receptors for insulin-stimulated GLUT4 translocation in adipocytes. Molecular and Cellular Biology 17 2425-2435.

Osborne SL, Wen PJ, Boucheron C, Nguyen HN, Hayakawa M, Kaizawa H, Parker PJ, Vitale N \& Meunier FA 2007 PIKfyve negatively regulates exocytosis in neurosecretory cells. Journal of Biological Chemistry 283 2804-2813.

Park CR \& Johnson LH 1955 Effect of insulin on transport of glucose and galactose into cells of rat muscle and brain. American Journal of Physiology 182 $17-23$.

Peck GR, Ye S, Pham V, Fernando RN, Macaulay SL, Chai SY \& Albiston AL 2006 Interaction of the Akt substrate, AS160, with the glucose transporter 4 vesicle marker protein, insulin-regulated aminopeptidase. Molecular Endocrinology 20 2576-2583.

Perera HK, Clarke M, Morris NJ, Hong W, Chamberlain LH \& Gould GW 2003 Syntaxin 6 regulates Glut4 trafficking in 3T3-L1 adipocytes. Molecular Biology of the Cell 14 2946-2958.

Persaud SJ, Asare-Anane H \& Jones PM 2002 Insulin receptor activation inhibits insulin secretion from human islets of Langerhans. FEBS Letters $\mathbf{5 1 0}$ 225-228.

Pilch PF 2008 The mass action hypothesis: formation of Glut4 storage vesicles, a tissue-specific, regulated exocytic compartment. Acta Physiologica 192 89-101.

Pilch PF, Wilkinson W, Garvey WT, Ciaraldi TP, Hueckstaedt TP \& Olefsky JM 1993 Insulin-responsive human adipocytes express two glucose transporter isoforms and target them to different vesicles. Journal of Clinical Endocrinology and Metabolism 77 286-289.

Proctor KM, Miller SC, Bryant NJ \& Gould GW 2006 Syntaxin 16 controls the intracellular sequestration of GLUT4 in 3T3-L1 adipocytes. Biochemical and Biophysical Research Communications 347 433-438.

Ralston E \& Ploug T 1996 GLUT4 in cultured skeletal myotubes is segregated from the transferrin receptor and stored in vesicles associated with TGN. Journal of Cell Science 109 2967-2978.

Ramm G, Larance M, Guilhaus M \& James DE 2006 A role for 14-3-3 in insulin-stimulated GLUT4 translocation through its interaction with the RabGAP AS160. Journal of Biological Chemistry 281 29174-29180.

Ribon V \& Saltiel AR 1997 Insulin stimulates tyrosine phosphorylation of the proto-oncogene product of c-Cbl in 3T3-L1 adipocytes. Biochemical Journal $324839-845$.

Ribon V, Printen JA, Hoffman NG, Kay BK \& Saltiel AR 1998 A novel, multifuntional $\mathrm{c}-\mathrm{Cbl}$ binding protein in insulin receptor signaling in 3T3-L1 adipocytes. Molecular and Cellular Biology 18 872-879.

Roper MG, Qian WJ, Zhang BB, Kulkarni RN, Kahn CR \& Kennedy RT 2002 Effect of the insulin mimetic L-783,281 on intracellular $\mathrm{Ca}^{2+}$ and insulin secretion from pancreatic beta-cells. Diabetes 51 S43-S49.

Ross SA, Herbst JJ, Keller SR \& Lienhard GE 1997 Trafficking kinetics of the insulin-regulated membrane aminopeptidase in 3T3-L1 adipocytes. Biochemical and Biophysical Research Communications 239 247-251.

Rutherford AC, Traer C, Wassmer T, Pattni K, Bujny MV, Carlton JG, Stenmark H \& Cullen PJ 2006 The mammalian phosphatidylinositol 5-phosphate 5-kinase (PIKfyve) regulates endosome-to-TGN retrograde transport. Journal of Cell Science 119 3944-3957.

Sakaue H, Ogawa W, Takata M, Kuroda S, Kotani K, Matsumoto M, Sakaue M, Nishio S, Ueno H \& Kasuga M 1997 Phosphoinositide 3-kinase is required for insulin-induced but not for growth hormone- or hyperosmolarity-induced glucose uptake in 3T3-L1 adipocytes. Molecular Endocrinology 11 1552-1562.

Sano H, Kane S, Sano E, Miinea CP, Asara JM, Lane WS, Garner CW \& Lienhard GE 2003 Insulin-stimulated phosphorylation of a Rab GTPase-activating protein regulates GLUT4 translocation. Journal of Biological Chemistry 278 14599-14602.

Sano H, Kane S, Sano E \& Lienhard GE 2005 Synip phosphorylation does not regulate insulin-stimulated GLUT4 translocation. Biochemical and Biophysical Research Communications 332 880-884.
Sano H, Eguez L, Teruel MN, Fukuda M, Chuang TD, Chavez JA, Lienhard GE \& McGraw TE 2007 Rab10, a target of the AS160 Rab GAP, is required for insulin-stimulated translocation of GLUT4 to the adipocyte plasma membrane. Cell Metabolism 5 293-303.

Sano H, Roach WG, Peck GR, Fukuda M \& Lienhard GE 2008 Rab10 in insulin-stimulated GLUT4 translocation. Biochemical Journal 411 89-95.

Saoudi Y, Rousseau B, Doussiere J, Charrasse S, Gauthier-Rouviere C, Morin N, Sautet-Laugier C, Denarier E, Scaife R, Mioskowski C et al. 2004 Calcium-independent cytoskeleton disassembly induced by BAPTA. European Journal of Biochemistry 271 3255-3264.

Sarbassov DD, Guertin DA, Ali SM \& Sabatini DM 2005 Phosphorylation and regulation of Akt/PKB by the rictor-mTOR complex. Science 307 1098-1101.

Satoh S, Nishimura H, Clark AE, Kozka IJ, Vannucci SJ, Simpson IA, Quon MJ, Cushman SW \& Holman GD 1993 Use of bismannose photolabel to elucidate insulin-regulated GLUT4 subcellular trafficking kinetics in rat adipose cells. Evidence that exocytosis is a critical site of hormone action. Journal of Biological Chemistry 268 17820-17829.

Scheffzek K, Ahmadian MR, Kabsch W, Wiesmuller L, Lautwein A, Schmitz F \& Wittinghofer A 1997 The Ras-RasGAP complex: structural basis for GTPase activation and its loss in oncogenic Ras mutants. Science $\mathbf{2 7 7}$ 333-338.

Seebohm G, Strutz-Seebohm N, Birkin R, Dell G, Bucci C, Spinosa MR, Baltaev R, Mack AF, Korniychuk G, Choudhury A et al. 2007 Regulation of endocytic recycling of KCNQ1/KCNE1 potassium channels. Circulation Research 100 686-692.

Semiz S, Park JG, Nicoloro SM, Furcinitti P, Zhang C, Chawla A, Leszyk J \& Czech MP 2003 Conventional kinesin KIF5B mediates insulin-stimulated GLUT4 movements on microtubules. EMBO Journal 22 2387-2399.

Shigematsu S, Khan AH, Kanzaki M \& Pessin JE 2002 Intracellular insulinresponsive glucose transporter (GLUT4) distribution but not insulinstimulated GLUT4 exocytosis and recycling are microtubule dependent. Molecular Endocrinology 16 1060-1068.

Shisheva A, Rusin B, Ikonomov OC, DeMarco C \& Sbrissa D 2001 Localization and insulin-regulated relocation of phosphoinositide 5-kinase PIKfyve in 3T3-L1 adipocytes. Journal of Biological Chemistry 276 11859-11869.

Shojaiefard M, Strutz-Seebohm N, Tavare JM, Seebohm G \& Lang F 2007 Regulation of the $\mathrm{Na}(+)$, glucose cotransporter by PIKfyve and the serum and glucocorticoid inducible kinase SGK1. Biochemical and Biophysical Research Communications 359 843-847.

Slot JW, Geuze HJ, Gigengack S, Lienhard GE \& James DE 1991 Immunolocalization of the insulin regulatable glucose transporter in brown adipose tissue of the rat. Journal of Cell Biology 113 123-135.

Smith RM, Charron MJ, Shah N, Lodish HF \& Jarett L 1991 Immunoelectron microscopic demonstration of insulin-stimulated translocation of glucose transporters to the plasma membrane of isolated rat adipocytes and masking of the carboxyl-terminal epitope of intracellular GLUT4. PNAS $\mathbf{8 8}$ 6893-6897.

Smithers NP, Hodgkinson CP, Cuttle M \& Sale GJ 2008 Insulin-triggered repositioning of munc18c on syntaxin-4 in GLUT4 signalling. Biochemical Journal 410 255-260.

St-Denis JF, Cabaniols JP, Cushman SW \& Roche PA 1999 SNAP-23 participates in SNARE complex assembly in rat adipose cells. Biochemical Journal 338 709-715.

Stephens L, Anderson K, Stokoe D, Erdjument-Bromage H, Painter GF, Holmes AB, Gaffney PR, Reese CB, McCormick F, Tempst P et al. 1998 Protein kinase B kinases that mediate phosphatidylinositol 3,4,5-trisphosphate-dependent activation of protein kinase B. Science 279 710-714.

Stöckli J, Davey JR, Hohnen-Behrens C, Xu A, James DE \& Ramm G 2008 Regulation of glucose transporter 4 translocation by the Rab guanosine triphosphatase-activating protein AS160/TBC1D4: role of phosphorylation and membrane association. Molecular Endocrinology 22 2703-2715.

Stokoe D, Stephens LR, Copeland T, Gaffney PR, Reese CB, Painter GF, Holmes AB, McCormick F \& Hawkins PT 1997 Dual role of phosphatidylinositol-3,4,5-trisphosphate in the activation of protein kinase B. Science 277 567-570. 
Stone S, Abkevich V, Russell DL, Riley R, Timms K, Tran T, Trem D, Frank D, Jammulapati S, Neff CD et al. 2006 TBC1D1 is a candidate for a severe obesity gene and evidence for a gene/gene interaction in obesity predisposition. Human Molecular Genetics 15 2709-2720.

Suzuki K \& Kono T 1980 Evidence that insulin causes translocation of glucose transport activity to the plasma membrane from an intracellular storage site. PNAS 77 2542-2545.

Tamborlane WV, Beck RW, Bode BW, Buckingham B, Chase HP, Clemons R, Fiallo-Scharer R, Fox LA, Gilliam LK, Hirsch IB et al. 2008 Continuous glucose monitoring and intensive treatment of type 1 diabetes. New England Journal of Medicine 359 1464-1476.

Tamori Y, Kawanishi M, Niki T, Shinoda H, Araki S, Okazawa H \& Kasuga M 1998 Inhibition of insulin-induced GLUT4 translocation by Munc18c through interaction with syntaxin 4 in 3T3-L1 adipocytes. Journal of Biological Chemistry 273 19740-19746.

Tani K, Shibata M, Kawase K, Kawashima H, Hatsuzawa K, Nagahama M \& Tagaya M 2003 Mapping of functional domains of gamma-SNAP. Journal of Biological Chemistry 278 13531-13538.

Tanner LI \& Lienhard GE 1987 Insulin elicits a redistribution of transferrin receptors in 3T3-L1 adipocytes through an increase in the rate constant for receptor externalization. Journal of Biological Chemistry 262 8975-8980.

Tanner LI \& Lienhard GE 1989 Localization of transferrin receptors and insulin-like growth factor II receptors in vesicles from 3T3-L1 adipocytes that contain intracellular glucose transporters. Journal of Cell Biology 108 1537-1545

Tanti JF, Grillo S, Gremeaux T, Coffer PJ, Van Obberghen E \& Le MarchandBrustel Y 1997 Potential role of protein kinase B in glucose transporter 4 translocation in adipocytes. Endocrinology 138 2005-2010.

Taylor EB, An D, Kramer HF, Yu H, Fujii NL, Roeckl KS, Bowles N, Hirshman MF, Xie J, Feener EP et al. 2008 Discovery of TBC1D1 as an insulin-, AICAR-, and contraction-stimulated signaling nexus in mouse skeletal muscle. Journal of Biological Chemistry 283 9787-9796.

Tengholm A \& Meyer T 2002 A PI3-kinase signaling code for insulintriggered insertion of glucose transporters into the plasma membrane. Current Biology 12 1871-1876.

Thurmond DC, Ceresa BP, Okada S, Elmendorf JS, Coker K \& Pessin JE 1998 Regulation of insulin-stimulated GLUT4 translocation by Munc18c in 3T3L1 adipocytes. Journal of Biological Chemistry 273 33876-33883.

Thurmond DC, Kanzaki M, Khan AH \& Pessin JE 2000 Munc18c function is required for insulin-stimulated plasma membrane fusion of GLUT4 and insulin-responsive amino peptidase storage vesicles. Molecular and Cellular Biology 20 379-388.

Voldstedlund M, Tranum-Jensen J \& Vinten J 1993 Quantitation of $\mathrm{Na}^{+} / \mathrm{K}(+)$-ATPase and glucose transporter isoforms in rat adipocyte plasma membrane by immunogold labeling. Journal of Membrane Biology 136 63-73.

Wang Q, Somwar R, Bilan PJ, Liu Z, Jin J, Woodgett JR \& Klip A 1999 Protein kinase B/Akt participates in GLUT4 translocation by insulin in L6 myoblasts. Molecular and Cellular Biology 19 4008-4018.

Welsh GI, Leney SE, Lloyd-Lewis B, Wherlock M, Lindsay AJ, McCaffrey MW \& Tavare JM 2007 Rip11 is a Rab11-and AS160-RabGAP-binding protein required for insulin-stimulated glucose uptake in adipocytes. Journal of Cell Science 120 4197-4208.
Whitehead JP, Molero JC, Clark S, Martin S, Meneilly G \& James DE 2001 The role of $\mathrm{Ca}^{2+}$ in insulin-stimulated glucose transport in 3T3-L1 cells. Journal of Biological Chemistry 276 27816-27824.

Wickner W \& Schekman R 2008 Membrane fusion. Nature Structural and Molecular Biology 15 658-664.

Widberg CH, Bryant NJ, Girotti M, Rea S \& James DE 2003 Tomosyn interacts with the t-SNAREs syntaxin 4 and SNAP23 and plays a role in insulin-stimulated GLUT4 translocation. Journal of Biological Chemistry 278 35093-35101.

Wilkie N, Wingrove PB, Bilsland JG, Young L, Harper SJ, Hefti F, Ellis S \& Pollack SJ 2001 The non-peptidyl fungal metabolite L-783,281 activates TRK neurotrophin receptors. Journal of Neurochemistry 78 1135-1145.

Worrall DS \& Olefsky JM 2002 The effects of intracellular calcium depletion on insulin signaling in 3T3-L1 adipocytes. Molecular Endocrinology 16 378-389.

Yamada E, Okada S, Saito T, Ohshima K, Sato M, Tsuchiya T, Uehara Y, Shimizu H \& Mori M 2005 Akt2 phosphorylates Synip to regulate docking and fusion of GLUT4-containing vesicles. Journal of Cell Biology 168 921-928.

Yang J \& Holman GD 1993 Comparison of GLUT4 and GLUT1 subcellular trafficking in basal and insulin-stimulated 3T3-L1 cells. Journal of Biological Chemistry 268 4600-4603.

Yip MF, Ramm G, Larance M, Hoehn KL, Wagner MC, Guilhaus M \& James DE 2008 CaMKII-mediated phosphorylation of the myosin motor Myo1c is required for insulin-stimulated GLUT4 translocation in adipocytes. Cell Metabolism 8 384-398.

Yu B, Poirier LA \& Nagy LE 1999 Mobilization of GLUT-4 from intracellular vesicles by insulin and $\mathrm{K}(+)$ depolarization in cultured $\mathrm{H} 9 \mathrm{c} 2$ myotubes. American Journal of Physiology 277 E259-E267.

Yu C, Cresswell J, Loffler MG \& Bogan JS 2007 The glucose transporter 4-regulating protein TUG is essential for highly insulin-responsive glucose uptake in 3T3-L1 adipocytes. Journal of Biological Chemistry 282 7710-7722.

Zeigerer A, Lampson MA, Karylowski O, Sabatini DD, Adesnik M, Ren M \& McGraw TE 2002 GLUT4 retention in adipocytes requires two intracellular insulin-regulated transport steps. Molecular Biology of the Cell $132421-2435$.

Zhang S \& Zhang ZY 2007 PTP1B as a drug target: recent developments in PTP1B inhibitor discovery. Drug Discovery Today 12 373-381.

Zhang B, Salituro G, Szalkowski D, Li Z, Zhang Y, Royo I, Vilella D, Diez MT, Pelaez F, Ruby C et al. 1999 Discovery of a small molecule insulin mimetic with antidiabetic activity in mice. Science 284 974-977.

Zhou QL, Park JG, Jiang ZY, Holik JJ, Mitra P, Semiz S, Guilherme A, Powelka AM, Tang X, Virbasius J et al. 2004 Analysis of insulin signalling by RNAi-based gene silencing. Biochemical Society Transactions 32 817-821.

\section{Received in final form 20 April 2009 \\ Accepted 22 April 2009 \\ Made available online as an Accepted Preprint 22 April 2009}

